\title{
The Role of Regulation and Bank Competition in Small Firm Financing: Evidence from the Community Reinvestment Act
}

Panagiotis Avramidis

The American College of Greece

George Pennacchi

University of Illinois at Urbana-Champaign

\section{Konstantinos Serfes}

Drexel University and

Federal Reserve Bank of Philadelphia Consumer Finance Institute

Visiting Scholar

\section{Kejia Wu}

Federal Reserve Bank of Philadelphia Supervision, Regulation, and Credit Department and Drexel University

ISSN: $1962-5361$

Disclaimer: This Philadelphia Fed working paper represents preliminary research that is being circulated for discussion purposes. The views expressed in these papers are solely those of the authors and do not necessarily reflect the views of the Federal Reserve Bank of Philadelphia or the Federal Reserve System. Any errors or omissions are the responsibility of the authors. Philadelphia Fed working papers are free to download at: https://philadelphiafed.org/researchand-data/publications/working-papers.
MP 22-0ิ

PUBLISHED

February 2022

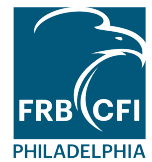




\title{
The Role of Regulation and Bank Competition in Small Firm Financing: Evidence from the Community Reinvestment Act*
}

\author{
Panagiotis Avramidis $^{\dagger} \quad$ George Pennacchi ${ }^{\ddagger} \quad$ Konstantinos Serfes $^{\S} \quad$ Kejia Wu $^{\mathbb{I I}}$
}

February 2, 2022"

\begin{abstract}
This paper analyzes how bank regulation that promotes greater access to credit impacts the financing of targeted small firms. It develops a model where banks compete with trade creditors to fund small firms and applies it to study the effects of the Community Reinvestment Act (CRA). The empirical tests reveal that a CRA-induced increase in bank loans reduces small firms' use of relatively expensive trade credit. The effect is more profound in low- and medium-income areas where financial constraints are tighter due to low bank competition. The effect is also larger for small firms that operate in trade credit-dependent industries.
\end{abstract}

Keywords: Competition; Regulation; Trade credit; Small business loans

JEL classifications: G14; G21; L13; L50

*We thank Giovanni Compiani (discussant), Omar Vasquez Duque (discussant), Ishan Ghose, Robert M. Hunt, Tristan Potter, and seminar participants at the Federal Reserve Bank of Philadelphia, Sultan Qaboos University, IIOC 2021, CRETE 2021, EARIE 2021 and CRESSE 2021, for useful comments and suggestions. Use of the National Establishment Time Series data was supported by the National Institute of Aging (grants 1R01AG049970, 3R01AG049970-04S1), Commonwealth Universal Research Enhancement (C.U.R.E.) program funded by the Pennsylvania Department of Health - 2015 Formula award - SAP \#4100072543, the Urban Health Collaborative at Drexel University, and the Built Environment and Health Research Group at Columbia University.

${ }^{\dagger}$ Alba Graduate Business School, The American College of Greece, Athens, Greece. pavramidis@alba.acg.edu.

*Department of Finance, University of Illinois, Champaign, IL, USA. gpennacc@illinois.edu.

${ }^{\S}$ School of Economics, LeBow College of Business, Drexel University, Philadelphia, PA, USA. ks346@drexel.edu.

IFederal Reserve Bank of Philadelphia, Philadelphia, PA, USA, and School of Economics, LeBow College of Business, Drexel University. kejia.wu@phil.frb.org.

"The views expressed in this paper are those of the authors and do not necessarily reflect the views of the Federal Reserve Bank of Philadelphia, the Federal Reserve Board of Governors, or the Federal Reserve System. 


\section{Introduction}

Despite technological innovations in lending, one-third of U.S. small firms report challenges in securing credit. ${ }^{1}$ Consolidation of the banking industry may contribute to these firms' difficulties. Bank loans are small firms' most common source of external financing, but since the 2008 financial crisis, the average number of banks serving local areas has declined, especially in low-income areas. Mills, Battisto, and Lieberman (2019) report that, while the number of banks per small firm is approximately the same in high-income and low-income areas, low-income areas have less than half as many banks and small firms. Moreover, small firms in low-income areas are more likely to use relatively expensive non-bank sources of financing. ${ }^{2}$

A decline in the number of banks is reason for concern because less bank competition reduces the formation of new firms (Black and Strahan (2002)) and closures of local bank branches lead to a persistent the decline in local small business lending (Nguyen (2019)). Since an area's small firms are important providers of goods and services and are also employers of local residents, the economic prospects of lowincome areas may be undermined. ${ }^{3}$ To expand credit availability and reduce the number of unbanked small firms and residents of low- and moderate-income (LMI) areas, policymakers have introduced programs to encourage bank lending to these communities. ${ }^{4}$ However, the impact on small firms targeted by these initiatives remains largely unexplored.

This study sheds light on the consequences of policy interventions on small firms by examining the effects of the Community Reinvestment Act (CRA), a U.S. regulation aimed at encouraging credit supply

\footnotetext{
${ }^{1}$ See the Federal Reserve's 2020 Small Business Credit Survey, which was taken in the second half of 2019 prior to the onset of the COVID-19 pandemic.

${ }^{2}$ Comparing U.S. zip code areas in the highest quartile of median family income to areas in the lowest quartile of median family income, the ratio of banks to small firms is approximately 0.01 in both. However, in 2018, there was an average of 4.3 (2.0) banks in high- (low-) income areas, down from an average of 4.5 (2.3) banks in 2007. In contrast, in 2016, high- (low-) income areas had an average of 0.7 (1.2) providers of relatively expensive alternative financial services.

${ }^{3}$ The U.S. Small Business Administration (SBA)'s 2019 Small Business Profile Report estimates that there are 30.7 million small firms in the U.S. accounting for $99.9 \%$ of total businesses and $47.3 \%$ of total U.S. employment. Importantly, $37 \%$ of high-tech workers work for small firms.

${ }^{4}$ The SBA, created in 1953, provides financing to young and growing small firms through several channels such as the 7(a) Loan Program and SBA 504 Certified Development Companies. The Community Reinvestment Act (CRA), enacted in 1977, encourages depository institutions to meet the credit needs of their local LMI communities. More recently, the Federal Reserve established the Main Street Lending Program to support lending to small and medium-sized organizations following the onset of the COVID-19 pandemic. This program terminated in January 2021.
} 
to LMI areas. First, we show that the areas that become newly eligible for CRA status experience a greater likelihood of a large increase in bank loans to small firms. Second, our analysis reveals that, on average, small firms in these newly CRA-eligible areas reduce their use of relatively expensive trade credit. For firms in industries that have traditionally relied on trade credit, there is an estimated 4-6 days shorter bill payment period and a 5.8-7.55\% increase in the proportion of firms that are likely to utilize early payment discounts or avoid late-payment penalties. This evidence is consistent with small firms substituting lower-cost bank loans for relatively expensive trade credit. Since trade credit discounts for early payment and penalties for late payment can be substantial (Petersen and Rajan (1994)), the implied reduction in these firms' cost of financing is likely to promote economic development of their local area. Third, we find that the effect of the CRA on firms' reduction in trade credit is more pronounced in areas with high bank concentration. In the absence of the CRA, such areas are likely to suffer from weak bank competition and more unbanked small firms that resort to trade credit. In summary, our findings are consistent with CRA-eligibility having the most impact on small firms in areas with low bank competition, allowing them to significantly reduce their dependence on expensive trade credit.

To motivate our empirical tests, we present a model where banks compete with trade creditors to fund the operations of small firms in a local market. The amount that a firm desires to borrow is declining in the interest rate that it is charged, and the firm also incurs a cost of applying for a bank loan that is higher the more distant it is from the bank. The model shows that when bank competition is high, all firms borrow from banks rather than higher-cost trade creditors. In contrast, when bank competition is low, a portion of firms become unbanked and rely solely on trade credit for financing. If banks are then subjected to a regulation that creates an additional incentive to lend, such as the CRA, the model shows that total lending in the market by banks always increases. However, a reduction in firms' use of trade credit occurs only in markets characterized by low bank competition.

Our empirical tests use a unique dataset constructed from a large-scale geocoding of National Establishment of Time Series (NETS) and FDIC Summary of Deposits (SOD) information. The dataset combines CRA loan data, small firm information, and bank branch information aggregated at the census tract level, which is the relevant geographic area for analyzing the effects of the CRA. This is because the CRA di- 
vides census tracts into two groups: upper-middle tracts with median family income (MFI) above $80 \%$ of the surrounding metropolitan area's MFI and low-moderate tracts with MFI below 80\%. Bank regulators' examinations that determine CRA ratings place heavy weight on whether a bank with branches serving low-moderate tracts is meeting the credit needs of small firms and residents in those tracts.

We use this dataset to examine whether CRA-induced lending affects small firms' use of trade credit in conjunction with the market's level of bank competition, an issue that is largely absent from existing empirical studies. Our tests exploit the fact that CRA-eligibility is based on a census tract's $80 \%$ MFI ratio, which allows us to use a "fuzzy" regression-discontinuity (RD) design. The logic of the RD design is that the probability that a local bank's small firm lending responds to CRA incentives jumps discontinuously at the $80 \%$ MFI cutoff, inducing heterogeneity in a regulatory treatment that is unrelated to potential confounding characteristics. However, examiners rate a bank's CRA compliance based on a geographic assessment area that is broader than a single census tract. Thus a tract's CRA eligibility may increase the probability that a bank lends to firms in that tract, but since it could still be in compliance by lending to other tracts, the probability need not be 1 . This probabilistic nature of a bank's tract-level compliance makes the fuzzy RD design more suitable compared to the sharp RD design that assumes deterministic tract-level compliance.

Our research contributes to a literature on bank competition and small firm financing. Berger, Saunders, Scalise, and Udell (1998) report that a decline in competition due to bank mergers leads to an initial shortfall in credit to small firms that is gradually eliminated by the entry of new banks and increased lending by existing banks. Cetorelli and Strahan (2006) provide evidence that greater bank competition is associated with higher numbers of small firms, consistent with easier credit access lowering barriers to firm entry. Also, by promoting competition, deregulation of bank branching has raised the rate of new business incorporations (Black and Strahan (2002)) and has increased small firms' access to bank loans at lower interest rates (Rice and Strahan (2010)). Our findings show that government regulatory incentives to expand bank lending can also be effective in alleviating small firms' credit constraints, especially when bank competition is low.

Our paper also relates to research on trade credit. Firms facing impediments to bank credit are more likely to resort to trade credit (Petersen and Rajan (1994), Petersen and Rajan (1997)), which explains why the use of trade credit is greater in countries with weak banking institutions (Fisman and Love (2003)). 
Lending to small firms is especially problematic due to their relative information opacity that requires more credit screening and monitoring from banks. Trade credit can alleviate this problem by incorporating in the lending relation the private information that suppliers have on their customers (Biais and Gollier (1997)). Our paper extends this literature by showing that when regulation creates added incentives for banks to increase lending, presumably by lowering their loan rates or the cost of applying for loans, small firms substitute bank credit for relatively more expensive trade credit.

Also relevant to our paper are studies showing that markets for lending to small firms are local in the sense that the distance between a small firm and its potential bank lenders matters (Petersen and Rajan (2002), Brevoort, Holmes, and Wolken (2010)). Compared to large corporations, there is often a lack of public "hard" information, such as audited financial statements, on small firms. Thus, banks often rely on the collection of private "soft" information through their relationships with small firms (Petersen and Rajan (1995)), and obtaining such information is less costly when banks and firms are physically close. Thus, the distance between firms and their potential lenders often proxies as a measure of soft information collection or the strength of a banking relationship (Agarwal and Hauswald (2010)). Our study suggests that when the distances between banks and small firms are larger because there are fewer banks in the local market, regulation can be effective in expanding access to bank credit.

Our paper also contributes to the more specialized literature examining the effects of the CRA. Most research studies the CRA's effects on residential mortgages (Bostic and Robinson (2003), Dahl, Evanoff, and Spivey (2010), Bhutta (2011), Agarwal, Benmelech, Bergman, and Seru (2012), Avery and Brevoort (2015), Ding and Nakamura (2020), and Begley and Purnanandam (2021)). This research finds mixed results regarding the effectiveness of the CRA on expanding mortgage lending. Fewer studies analyze the CRA's effects on lending to small firms. Zinman (2002) finds evidence that banks facing greater CRA incentives due to a 1995 CRA reform increased their lending to small firms but not in CRA-eligible LMI areas. ${ }^{5}$ In contrast, Bostic and Lee (2017) find that CRA-eligible census tracts experience more small firm lending than similar CRA-ineligible tracts during the periods 1996-2002 and 2012-2014, but not during 2003-2011. Ding, Lee, and Bostic (2018) analyze a 2013 adjustment in metropolitan area boundaries that

\footnotetext{
${ }^{5} \mathrm{He}$ also examined the counties where these banks operated and found evidence of a decline in personal bankruptcies but no change in employment, payrolls, or business bankruptcies.
} 
led to an exogenous change in some census tracts' CRA eligibility. They find that a tract losing CRA eligibility led to a decline in lending to small firms, but there was not a statistically significant increase in lending to small firms when a tract gained eligibility. Kim, Lee, and Earle (2021) use 2004-2016 panel data and find that the number and amount of loans to small firms increase in tracts that become eligible for the CRA.

Research analyzing the CRA's effects on small firms has been confined to determining whether it changes the quantity of banks' small business loans. Our research goes a step further by addressing whether CRA-induced lending has benefited targeted small firms. This is an important issue for evaluating the economic efficacy of a government initiative. Our results document the conditions under which the CRA leads to a reduction in small firms' use of expensive trade credit.

The paper is organized as follows. Section 2 presents a model of bank lending and trade credit with its derivations relegated to the Appendix. Our empirical methodology and data are discussed in Section 3, while Section 4 presents the empirical findings. Section 5 concludes.

\section{A model of bank lending and trade credit}

This section extends the model of Salop (1979) and Basu, Basu, and Ingene (2021) to study competition for lending to small firms. Small firms choose to borrow from local banks or their trade creditors and have borrowing demands that are linear, decreasing functions of the borrowing rate. We show that when bank competition is low, some small firms are unbanked and rely on trade credit. We also analyze the effects of a regulation, such as the CRA, that provides incentives for banks to expand lending to small firms. 


\subsection{Assumptions}

There is a continuum of identical small firms located uniformly around a circle with unit circumference. Small firms fund their operations by borrowing from trade creditors or banks. A small firm's demand for borrowing is a linear, decreasing function of its borrowing rate, $r .{ }^{6}$ The firm's amount borrowed, $B$, satisfies

$$
B(r)=a-b r
$$

where $a$ and $b$ are positive constants. Each firm has the option to borrow by paying trade credit late at an effective interest rate equal to $r_{T}$ that is assumed to be exogenous and the same for all firms. A justification for this assumption is that trade credit offered to small firms is typically standardized. Vendors and suppliers commonly offer invoice terms of " $2 / 10$, net 30 ," which means that the firm receives a $2 \%$ discount if it pays its bill within 10 days. Otherwise, the full amount is due within 30 days. Paying "late" on the $30^{\text {th }}$ day relative to paying the discounted bill on the $10^{\text {th }}$ day implies an effective annualized interest rate of over 40\%. Paying beyond the term of 30 days can also incur costly late-payment penalties. However, it is assumed that small firms have a positive demand for borrowing at this high trade credit rate so that $r_{T}<\frac{a}{b}$, where $\frac{a}{b}$ is the maximum borrowing rate at which there is nonnegative demand.

Alternatively, small firms may borrow from one of $n \geq 2$ banks that are symmetrically located around the circle. A bank's cost of funding a loan is assumed to equal $r_{F}$ per unit of loan made. This cost combines the bank's weighted cost of deposit (debt) and equity financing and its cost of credit screening and monitoring a firm. It is assumed that $r_{F}<r_{T}$ so that it is feasible for banks to profitably lend to at least some small firms.

Each firm owner incurs a disutility cost of $t$ per unit distance traveled to apply for a loan at one of the banks. Distance from a bank can proxy for a firm's initial information opacity, so that the bank requires that more distant firms provide greater documentation and undergo a longer origination process to qualify for a loan (Petersen and Rajan (2002), Brevoort, Holmes, and Wolken (2010)). For example, banks tend

\footnotetext{
${ }^{6}$ Evidence in the 2020 Federal Reserve Small Business Credit Survey supports the assumption that the demand for borrowing is elastic. Of the firms that obtained less than the amount of financing that they sought, $20 \%$ declined some or all of the full amount, with $73 \%$ of these firms indicating that the interest rate was too high.
} 
to possess less soft information on more distant small firms, thereby requiring them to provide more hard information that can be a burden for small firms to compile and document. ${ }^{7}$

If small firm is distance $x$ from a bank that charges a loan interest rate of $r_{L}$, the firm is assumed to borrow from the bank if the amount borrowed at the bank loan rate less the disutility of transportation costs is greater than its amount borrowed at the trade credit rate; that is, $B\left(r_{L}\right)-x t>B\left(r_{T}\right)$. Thus, the firm chooses to borrow from a bank when:

$$
\begin{aligned}
a-b r_{L}-x t & >a-b r_{T} \\
\Rightarrow & \frac{b}{t}\left(r_{T}-r_{L}\right)>x .
\end{aligned}
$$

Otherwise, the firm prefers to borrow using trade credit. ${ }^{8}$

Let us consider the equilibrium loan rate, $r_{L}$, charged by profit-maximizing banks for symmetric, Bertrand-Nash equilibria that have a short-run nature in the sense that the number of banks, $n$, is fixed. Similar to Salop (1979), different types of equilibria occur depending on the number of banks. ${ }^{9}$

\subsection{Local monopoly equilibrium}

When there are sufficiently few banks in the market, a bank's profit maximizing loan rate is such that some small firms farthest from banks find it cheaper to borrow using trade credit. Hence, in equilibrium, each bank directly competes with trade creditors and makes loans to only a portion of small firms closest to the bank. The Appendix shows that, in this case, each bank's equilibrium profit maximizing loan rate is:

\footnotetext{
${ }^{7}$ The Federal Reserve's 2020 Small Business Credit Survey reports that small firms are more likely to complain of a long wait and a difficult application process when applying for loans from banks compared to nonbank lenders. In contrast, small firms are more likely to complain of a high interest rate or unfavorable repayment terms when applying for loans from nonbank lenders compared to banks.

${ }^{8} \mathrm{Basu}$, Basu, and Ingene (2021) assume that the disutility traveling cost, $x t$, is proportional to the amount of the product demanded. In the case of a firm applying for a loan, we think that a fixed cost is more realistic compared to one that is proportional to the loan size. However, the model results are qualitatively similar if travel costs are proportional to the loan size.

${ }^{9}$ We follow Salop (1979) and assume that each bank sets a uniform loan rate. However, our qualitative results on the effects of competition and the CRA on small firms' use of trade credit are robust to the alternative assumption that loan rates can differ based on a firm's distance (Thisse and Vives (1988)). Specifically, enabling a bank to set lower rates for more distant firms would result in a local monopoly equilibrium with unbanked firms relying on trade credit if the market has few enough banks. In this low-competition setting, a CRA-type regulation can expand bank lending and reduce firms' use of trade credit.
} 


$$
r_{L}=\frac{1}{3}\left(r_{T}+\frac{a}{b}+r_{F}-\sqrt{\left(r_{T}+\frac{a}{b}-r_{F}\right)^{2}+r_{F}\left(r_{T}+\frac{a}{b}\right)-3 r_{T} \frac{a}{b}}\right),
$$

which depends solely on $r_{T}, a / b$, and $r_{F}$. The Appendix also shows that each bank's equilibrium quantity of loans, denoted $Q_{M}$, and the equilibrium proportion of small firms obtaining bank loans, denoted $\rho_{M}$, equal:

$$
\begin{aligned}
& Q_{M}= \frac{2 b^{2}}{9 t}\left[2 \frac{a}{b} r_{T}-\left(\frac{a}{b}-r_{T}\right)^{2}-2 r_{F}\left(\frac{a}{b}+r_{T}-r_{F}\right)\right. \\
&\left.+\left(\frac{a}{b}+r_{T}-2 r_{F}\right) \sqrt{\left(r_{T}+\frac{a}{b}-r_{F}\right)^{2}+r_{F}\left(r_{T}+\frac{a}{b}\right)-3 r_{T} \frac{a}{b}}\right] \\
& \rho_{M}=\frac{2 b n}{3 t}\left[2 r_{T}-\frac{a}{b}-r_{F}+\sqrt{\left(r_{T}+\frac{a}{b}-r_{F}\right)^{2}+r_{F}\left(r_{T}+\frac{a}{b}\right)-3 r_{T} \frac{a}{b}}\right] .
\end{aligned}
$$

Since the local monopoly equilibrium can occur only if $\rho_{M}<1$, this condition is equivalent to an upper bound on the number of banks:

$$
n<n_{M} \equiv \frac{3 t}{2 b\left[2 r_{T}-\frac{a}{b}-r_{F}+\sqrt{\left(r_{T}+\frac{a}{b}-r_{F}\right)^{2}+r_{F}\left(r_{T}+\frac{a}{b}\right)-3 r_{T} \frac{a}{b}}\right]} .
$$

\subsection{Competitive equilibrium}

When there are sufficiently many banks in the market, each bank competes with its two neighboring banks to lend to small firms. In equilibrium, all firms choose to borrow from banks and none use trade credit. The Appendix shows that in this competitive case the symmetric Bertrand-Nash equilibrium bank loan rate is:

$$
r_{L}=r_{F}+\frac{1}{2} m+\frac{t}{b n}-\sqrt{\frac{m^{2}}{4}+\left(\frac{t}{b n}\right)^{2}}
$$


where $m \equiv \frac{a}{b}-r_{F}$ is the maximum interest margin at which borrowing is nonnegative. Each bank's quantity of loans made to small firms equals:

$$
Q_{C}=\frac{b}{n}\left(\frac{1}{2} m-\frac{t}{b n}+\sqrt{\frac{m^{2}}{4}+\left(\frac{t}{b n}\right)^{2}}\right) .
$$

Of course when this competitive equilibrium holds, firms that are farthest from banks at the distance $x=\frac{1}{2 n}$ must continue to prefer bank loan financing rather than trade credit. In other words, equation (2.2) must hold where $x=\frac{1}{2 n}$ and $r_{L}$ is given by equation (2.7). This requirement is equivalent to the number of banks, $n$, satisfying the condition

$$
n\left[r_{T}-\frac{\frac{a}{b}+r_{F}}{2}+\sqrt{\frac{m^{2}}{4}+\left(\frac{t}{b n}\right)^{2}}\right]>\frac{3 t}{2 b}
$$

Thus, when $n$ is sufficiently large such that condition (2.9) holds, the competitive equilibrium obtains and the proportion of small firms obtaining bank loans, $\rho$, equals 1 so that no firm borrows using trade credit.

\subsection{Kinked equilibrium}

Recall that $n_{M}$, defined in inequality (2.6), is the upper bound on the number of banks in the market for the monopoly equilibrium to hold. Also, let $n_{C}$ be the value of $n$ such that inequality (2.9) holds with equality, so that it is the lower bound on the number of banks for the competitive equilibrium to hold. The Appendix shows that there exists $n$ such that $n_{M}<n<n_{C}$. In other words, there are intermediate numbers of banks where neither the monopoly equilibrium nor the competitive equilibrium holds. Salop (1979) describes this third type of equilibrium as a "kinked" equilibrium because at the point where the proportion of small firms receiving bank loans, $\rho$, equals 1 , the elasticity of (loan) demand changes discretely from the monopoly equilibrium to the competitive equilibrium, producing a kink in the loan demand curve. 
The kinked equilibrium is characterized by the maximum bank loan rate such that $\rho=1$. Hence, at this loan rate, the small firms farthest from banks at the distance $x=\frac{1}{2}$ are indifferent between borrowing from banks and trade creditors. This kinked equilibrium loan rate equals:

$$
r_{L}=r_{T}-\frac{1}{2 n b}
$$

and each bank's quantity of loans equals

$$
Q_{K}=\frac{1}{n}\left(a-b r_{T}+\frac{t}{2 n}\right)
$$

Since the kinked equilibrium loan rate is the maximum rate conditional on all firms choosing banks, we have that the proportion of firms obtaining bank loans, $\rho$, equals 1 , the same as the competitive equilibrium.

\subsection{Effects of CRA policy}

To summarize our model's results, the equilibrium bank loan rate equals:

$$
r_{L}= \begin{cases}\frac{1}{3}\left(r_{T}+\frac{a}{b}+r_{F}-\sqrt{\left(r_{T}+\frac{a}{b}-r_{F}\right)^{2}+r_{F}\left(r_{T}+\frac{a}{b}\right)-3 r_{T} \frac{a}{b}}\right) & \text { if } n<n_{M} \\ r_{T}-\frac{t}{2 n b} & \text { if } n_{M} \leq n \leq n_{C} \\ r_{F}+\frac{1}{2} m+\frac{t}{b n}-\sqrt{\frac{m^{2}}{4}+\left(\frac{t}{b n}\right)^{2}} & \text { if } n_{C}<n,\end{cases}
$$

and the proportion of small firms obtaining bank loans is

$$
\rho= \begin{cases}\rho_{M} & \text { if } n<n_{M} \\ 1 & \text { if } n_{M} \leq n\end{cases}
$$

where $\rho_{M}<1$ is given in equation (2.5).

The CRA, enacted in 1977, was motivated by the perception that many banks collected deposits from their branches located in LMI areas but extended insufficient credit to residents and small firms in these areas. Thus, the goal of the CRA is to expand bank lending to LMI areas beyond what banks would choose 
in the absence of this legislation. Banks are regularly examined and rated for CRA compliance by their federal regulators. These ratings are released to the public and carry consequences. First, federal regulators must consider a bank's CRA performance when evaluating its application for a merger or acquisition, for its formation of a branch, or for other business activity. Second, and more indirectly, community activists and public interest groups monitor banks and can impose public relations costs on those with poor CRA performance. Hence, they provide an independent source of bank discipline.

Given these penalties from noncompliance, one would expect that, ceteris paribus, a bank's amount lent in CRA-eligible markets exceeds that in CRA-ineligible markets. Indeed, a Federal Reserve survey of banks finds that a majority engaged in some lending in CRA-eligible areas that they would not have done in the absence of the law (Avery, Bostic, and Canner (2005)). A corollary to this behavior is that if a market transitioned from being CRA-ineligible to CRA-eligible due to a small change in its LMI status, banks would lower loan rates below those predicted by equation (2.12), thereby expanding lending beyond that predicted by our model's $Q_{M}, Q_{K}$, and $Q_{C}$ in equations (2.4), (2.11), and (2.8), respectively.

However, our model predicts that such a lowering of loan rates and an expansion of bank lending would have disparate effects on small firms' use of trade credit across different types of markets. Equation (2.13) shows that CRA eligibility reduces firms' use of trade credit only for markets characterized by the monopoly equilibrium since only in these markets are there "unbanked" firms that depend on trade credit in the absence of the CRA. Consequently, we expect that CRA eligibility will lead to a greater reduction in small firms' use of trade credit in banking markets characterized by high concentration and low competition.

The next section discusses the design of our empirical analysis that tests these model predictions.

\section{Empirical methodology and data}

This section discusses how an area's CRA eligibility is determined based on its LMI status, how our empirical tests exploit this eligibility, the data used in the tests, and summary statistics of the data. 


\subsection{Treatment of census tracts}

Recall that a bank's CRA rating is heavily weighted by the bank's lending in census tracts that are designated as LMI areas. A census tract is an LMI area or "CRA-eligible" if its MFI is less than $80 \%$ of its surrounding metropolitan area's MFI based on information provided by the U.S. Census. According to the Federal Financial Institutions Examination Council (FFIEC), until the end of 2011, a tract's CRA eligibility was based on MFIs determined from year 2000 census data. From January 2012 forward, eligibility was based on MFIs using year 2010 census data. As a result, approximately $15 \%$ of the tracts that were marginally ineligible in 2011 using the 2000 census became CRA-eligible tracts in 2012 using the 2010 census.

Our tests compare these newly eligible census tracts relative to census tracts that remained ineligible using a RD design. Prior empirical studies analyzing the effects of the CRA on lending have also used an RD approach, including Avery, Calem, and Canner (2003), Bhutta (2011), Avery and Brevoort (2015), Bostic and Lee (2017) and Kim, Lee, and Earle (2021). However, unlike this prior work that uses a sharp RD design, we employ a fuzzy RD design. The difference is that we interpret the CRA's incentive on lending in an eligible census tract as probabilistic rather than deterministic. In other words, using the language of the RD literature, some banks are "noncompliant" in that they do not necessarily have an incentive to increase their lending to a particular newly CRA-eligible census tract. Failing to consider the probabilistic nature of a loan increase induced by CRA eligibility means that the actual effect on the outcome variable is underestimated because all eligible tracts are equally counted, independent of whether the bank actually increased its lending.

The reason for a bank's possible noncompliance is that its overall CRA rating is based on an examination of its lending in a broader geographic assessment area that the bank can reasonably serve with its main office and branches. The implication is that a census tract's eligibility may increase the probability that a bank has a greater incentive to lend in that tract, but the bank could still obtain a satisfactory CRA rating by lending to other CRA-eligible tracts within a county or MSA where the bank has a presence. Consistent with our assumption that banks may be noncompliant in lending to small firms in CRA-eligible tracts is the Federal Reserve survey evidence reported in Avery, Bostic, and Canner (2005). Surveyed banks responded that they 
were significantly less likely to establish a special lending program in CRA-eligible areas for the case of small business loans compared to the case of residential mortgages. ${ }^{10}$

Therefore, we need to identify the eligible tracts that actually experience a CRA-induced increase in bank loan supply. This supply-driven loan growth is more easily observed among newly eligible tracts compared to census tracts that have remained eligible based on the 2000 census data and thus had a more predictable supply of loans ever since. Focusing on newly eligible tracts where banks are, presumably, less likely to have built long-term relationships with local firms helps to avoid any confounding effect from relationship lending on the firm's use of trade credit.

Our RD tests take the following form. Let $X_{i}$ be census tract $i$ 's ratio of MFI to the MFI of the surrounding metropolitan area. According to the CRA, loans to small firms in this tract become CRA eligible when $X_{i}<c=80 \%$, generating a discontinuity at the cutoff, $c$. We define as "treatment" a CRA-induced substantial growth in small firm loans, and we denote it with the dummy variable $T_{i}$. In sharp RD design, assignment to treatment coincides with the actual treatment, and thus, the jump in the probability of observing a substantial increase in small firm loans at the cutoff is from zero to one. As discussed above, compliance in the case of the CRA is imperfect due to a bank's lending being assessed over a broader area than a single eligible census tract. Therefore, we employ a fuzzy RD design where the probability of a substantial increase in small firm loans at the cutoff is less than one.

Specifically, the fuzzy RD design assumes that newly eligible tracts are more likely to experience a substantial increase in small firm loan supply disproportionate to that of census tracts that remain ineligible:

$\lim _{\epsilon \rightarrow 0} \mathrm{E}\left[T_{i} \mid X_{i}=c-\epsilon\right]-\lim _{\epsilon \rightarrow 0} \mathrm{E}\left[T_{i} \mid X_{i}=c+\epsilon\right]=\lim _{\epsilon \rightarrow 0} \operatorname{Pr}\left(T_{i}=1 \mid X_{i}=c-\epsilon\right)-\lim _{\epsilon \rightarrow 0} \operatorname{Pr}\left(T_{i}=1 \mid X_{i}=c+\epsilon\right)>0$.

Now let $Y_{i}$ denote an outcome variable for census tract $i$, such as a measure of the amount of trade credit used by small firms in census tract $i$. There should be no reason, other than the eligibility of the tract, for this outcome variable to be a discontinuous function of the tract's MFI ratio. This discontinuity of $Y_{i}$ is:

\footnotetext{
${ }^{10}$ Note: $54.9 \%$ of the respondents had set up a CRA Special Lending Program to expand residential mortgage lending, but only $10.4 \%$ of the respondents had set up such a program to expand small business lending. While banks could still expand lending without these programs, their existence indicates the strength of incentives to increase lending.
} 


$$
\lim _{\epsilon \rightarrow 0} \mathrm{E}\left[Y_{i} \mid X_{i}=c-\epsilon\right]-\lim _{\epsilon \rightarrow 0} \mathrm{E}\left[Y_{i} \mid X_{i}=c+\epsilon\right]
$$

Based on equations (3.1) and (3.2), the fuzzy RD effect of the eligibility-induced substantial increase in loans to small firms on the outcome variable $Y_{i}$ is defined as:

$$
\tau=\frac{\lim _{\epsilon \rightarrow 0} \mathrm{E}\left[Y_{i} \mid X_{i}=c-\epsilon\right]-\lim _{\epsilon \rightarrow 0} \mathrm{E}\left[Y_{i} \mid X_{i}=c+\epsilon\right]}{\lim _{\epsilon \rightarrow 0} \mathrm{E}\left[T_{i} \mid X_{i}=c-\epsilon\right]-\lim _{\epsilon \rightarrow 0} \mathrm{E}\left[T_{i} \mid X_{i}=c+\epsilon\right]}=\frac{\mu_{Y^{-}}-\mu_{Y^{+}}}{\mu_{T^{-}}-\mu_{T^{+}}}
$$

where $\mu_{U^{ \pm}}$denotes the limit of the expectation of variable $U$ as $X_{i}$ approaches $c$ from below (-) or above $(+)$.

\subsection{Estimation methodology}

Estimation of the eligibility effect $\tau$ is performed using local polynomial estimators. Functions for $T_{i}$ and $Y_{i}$ above and below the cutoff are approximated by means of weighted polynomial regressions with weights computed by applying a kernel function on the distance of each observation to the cutoff point. We employ the robust local linear polynomial estimator of Calonico, Cattaneo, and Titiunik (2014), which corrects for the bias of bandwidth. Formally, the conventional local linear estimator for a positive bandwidth $h$, kernel function $K_{h}=K\left(\left(X_{i}-c\right) / h\right)$, and a set of covariates $\mathbb{Z}_{i}$ is found by optimizing the equations:

$$
\begin{aligned}
& \hat{\mu}_{U^{-}}=\arg \min _{\left\{b_{0}, b_{1}\right\}} \sum_{n}\left(\mathbb{1}\left(X_{i}<c\right)\left(U_{i}-b_{0}-b_{1}\left(X_{i}-c\right)-\gamma \mathbb{Z}_{i}\right)^{2} K_{h}\right. \\
& \hat{\mu}_{U^{+}}=\arg \min _{\left\{b_{0}, b_{1}\right\}} \sum_{n}\left(\mathbb{1}\left(X_{i} \geq c\right)\left(U_{i}-b_{0}-b_{1}\left(X_{i}-c\right)-\gamma \mathbb{Z}_{i}\right)^{2} K_{h},\right.
\end{aligned}
$$

where the random variable $U_{i}$ is equal to either $T_{i}$ or $Y_{i}$. Equations (3.4) and (3.5) use the recommended choice of local linear polynomial approximation, $b_{0}+b_{1}\left(X_{i}-c\right)$, which has smaller asymptotic bias (Cattaneo, Idrobo, and Titiunik (2019)). Moreover, in the analysis that follows, we employ the Epanechnikov kernel function, often called the optimal kernel, because it yields the lowest possible asymptotic mean squared error (MSE). In additional robustness tests, we also use the Uniform kernel function. 
The probability of treatment (e.g., a substantial small firm loan increase) is estimated by the local linear RD estimator that employs a local-quadratic bias correction:

$$
\hat{\tau}_{T}=\hat{\mu}_{T^{-}}-\hat{\mu}_{T^{+}}-h_{T}^{2} \mathbb{B}_{T}\left(h_{T}, b_{T}\right)
$$

where we denote $\mathbb{B}_{U}\left(h_{U}, b_{U}\right)$ as the bias correction factor for variable $U$ and $b_{U}$ is the bias-correction bandwidth. ${ }^{11}$ Finally, the bias-corrected local linear fuzzy RD estimator of the effect of the treatment on the outcome variable (e.g., trade credit usage) that employs a local quadratic estimate of the leading bias is:

$$
\hat{\tau}_{Y}=\frac{\hat{\mu}_{Y^{-}}-\hat{\mu}_{Y^{+}}}{\hat{\mu}_{T^{-}}-\hat{\mu}_{T^{+}}}-h_{Y}^{2} \mathbb{B}_{Y}\left(h_{Y}, b_{Y}\right) .
$$

The choice of bandwidth, $h$, is consequential because, given the choices of local linear approximation and kernel function, the accuracy of the approximation is essentially determined by the bandwidth. For all point estimators of the RD effects, we use the recommended MSE optimal plug-in bandwidth $h_{M S E}$, which minimizes the asymptotic variance and bias of the estimator (Cattaneo, Idrobo, and Titiunik (2019)). Additional robustness tests use the common MSE-optimal bandwidth selector for the sum of regression estimates bandwidth $h_{M S E, S U M}$, which is useful for minimizing overfitting. Furthermore, we use the CER optimal bandwidth $h_{C E R}$, which minimizes the asymptotic coverage error rate of the bias corrected confidence interval, for inference in the falsification tests. Finally, we use the cluster at census tract level robust plug-in residuals variance estimator to compute the variance-covariance matrix.

\subsection{Data}

Our empirical analysis uses data from three sources. First, from the FFIEC, we obtain information on small business loans made by individual banks. CRA regulations require that banks above given asset size thresholds report their commercial loans extended to small firms. ${ }^{12}$ We focus on loans originated to small

\footnotetext{
${ }^{11}$ See Calonico, Cattaneo, and Titiunik (2014) for more details.

${ }^{12}$ Banks include national banks, state Federal Reserve member banks, state nonmember banks, and savings associations. The FFIEC reports the asset-size filing threshold each year, and it is typically over $\$ 1$ billion.
} 
firms with gross annual revenues of $\$ 1$ million or less. The reported annual loan data refer to new loans and include the total number of loans and the total loan amount at origination aggregated at the U.S. Census tract level. CRA small business lending data cover roughly $86 \%$ of all loans of $\$ 1$ million or less (Greenstone, Mas, and Nguyen (2020)).

The FFIEC also publishes census data at the tract level. ${ }^{13}$ Variables that pertain to our analysis include MFIs for each census tract and its surrounding MSA or Metropolitan Division (MD). As mentioned earlier, if a census tract is within a bank's assessment area, loans made in that tract qualify for CRA status based on the tract's MFI relative to the MFI in its MSA/MD. ${ }^{14}$ Therefore, updates of tract MFI or MSA/MD MFI can change a tract's CRA eligibility. According to the FFIEC, 2011 MFI data for both census tracts and MSAs/MDs are based on the 2000 census, while 2012 MFI data are based on the 2010 census. Consistent with this income data, census tracts are classified based on the 2000 census for loans originated in 2011, while tracts are classified based on the 2010 census for loans originated in 2012. Additional demographic variables used in our analysis include the census tract's total population and its minority population as a percentage of total population.

Second, data on small firms are obtained from the National Establishment Time Series (NETS) compiled by Walls \& Associates. Because small firms are mainly single establishments, we use the terms 'firm' and 'establishment' interchangeably. Among all NETS establishments, we exclude those from North American Industry Classification System (NAICS) industries of Agriculture, Forestry, Fishing, and Hunting whose CRA loans are reported separately, and from Education Services and Public Administration, which typically do not depend on small business bank loans. We further drop establishments with a missing NAICS code, data year, or employment numbers, and also inactive establishments such as those with a bankruptcy filing indicator. Following the literature of the NETS database (Barnatchez, Crane, and Decker (2017)), we also exclude establishments reporting only one employee, i.e., self-employed. Finally, we use the Small Business Administration (SBA)'s definition to characterize an establishment as a small firm, namely, manufacturing

\footnotetext{
${ }^{13} \mathrm{~A}$ census tract, which is a relatively permanent subdivision of a county, generally contains between 1,200 and 8,000 inhabitants and varies in size across urban and rural areas.

${ }^{14}$ For tracts located outside a MSA/MD, the surrounding area MFI is the statewide non-MSA/MD MFI.
} 
industry firms with less than 500 employees and nonmanufacturing industry firms with three-year average annual sales below $\$ 7.5$ million.

NETS also provides us with small firms' PAYDEX scores, which measure how quickly a firm pays its trade creditors. PAYDEX is compiled by Dun \& Bradstreet (D\&B) based on reports from each firm's vendors and suppliers. It uses a rolling, 12-month record of a firm's payments to compute a value-weighted average of the number of days it takes the firm to pay its bills relative to each bill's "terms" or due date. For example, if a vendor's bill specified " $2 / 10$, net 30," 30 days would be the bill's terms, so that the firm would receive the $10 \%$ discount by paying at least 20 days sooner than terms. PAYDEX scores range between 100 and 1, where scores of 100, 90, and 80 equate to paying sooner than terms by 30,20 , and 0 days, respectively. PAYDEX scores of 70, 60, 50, 40, 30, 20, and 10 equate to paying beyond terms by 15,22 , $30,60,90,120$, and over 120 days, respectively. ${ }^{15}$

To assign establishments to census tracts, we perform geocoding from an establishment's latitude and longitude provided by NETS to determine within which tract's boundary it falls, where tract boundary files were downloaded from the U.S. Census website. Consistent with CRA lending data, NETS data before 2012 are mapped to census tracts based on the 2000 census map, while 2012 NETS data are mapped based on 2010 census map. ${ }^{16}$ For each year, we calculate the total number of small firms and their average PAYDEX scores per census tract. In addition, we calculate the proportion of firms with PAYDEX scores higher than 70. We choose to focus on a 70 PAYDEX score threshold for two reasons. First, 70 is approximately the average PAYDEX score observed among small firms in our sample which makes it a suitable cut off compared to other scores. ${ }^{17}$ Second, a firm with a score below 70 is paying later than a bill's terms or due date, implying that it is missing out on most early-payment discounts and may be subject to late-payment penalties. As such, small firms with a score below 70 are likely resorting to relatively expensive trade credit.

\footnotetext{
${ }^{15}$ See www.dandb.com/glossary/paydex/. Note that PAYDEX is based exclusively on the speed at which trade credit from vendors and suppliers is paid and does not include the speed at which other obligations, such as bank loans, are paid.

${ }^{16} \mathrm{We}$ exclude establishments that moved during our sample period to avoid potential confounding factors that led a firm to relocate to obtain a CRA loan. We also drop establishments with missing coordinates.

${ }^{17}$ Only $0.5 \%$ of firms have a PAYDEX score of 80 or above, $73.1 \%$ have a score between 70 and 80 , and $26.4 \%$ have a score of 70 or below.
} 
Finally, bank branch data come from the Summary of Deposits (SOD), the annual report of branch office deposits for all FDIC-insured institutions including insured U.S. branches of foreign banks. Following standard treatment, we keep only brick-and-mortar branches and remove any branches with missing or duplicated physical addresses. SOD reports latitudes and longitudes of most physical branches, and for those that are missing this data, we impute coordinates from geocoding the branch addresses.

To estimate the relevant bank branches to which a small firm in a given census tract would likely have access, we draw a circle with a search radius around the population center of each census tract. ${ }^{18}$ We assume a small firm searches for bank branches within 2 miles around the center of a tract in an urban area, 5 miles in a mixed urban/rural area, and 10 miles in a rural area. ${ }^{19}$ Any bank branch having coordinates within the relevant search radius from the tract center is considered to serve small firms in that tract. Thus, we are able to identify for each year all bank branches serving a particular census tract.

We calculate the Herfindahl-Hirschman Index (HHI) of banks serving each tract by estimating their market shares of deposits in branches serving that tract. ${ }^{20}$ We also calculate separately the total number of branches of large banks, defined as banks with assets exceeding the annual CRA regulatory size threshold, and the total number of branches of small banks, defined as banks with assets below that threshold. The large versus small bank distinction is potentially important since prior research suggests that small banks are more inclined to fund local small firms (Berger, Miller, Petersen, Rajan, and Stein (2005)). In addition, small banks below the CRA regulatory threshold are subject to fewer reporting requirements and may face less pressure to embrace CRA mandates (Marsico (2005)).

\subsection{Summary statistics}

Our sample is composed of observations at the census tract level during the years 2011 and 2012. It includes two types of census tracts: the newly CRA-eligible tracts after the incorporation of the 2010 census data and

\footnotetext{
${ }^{18}$ Tract population center files are downloaded from the census website (https://www.census.gov/geographies/referencefiles/time-series/geo/centers-population.2010.html).

${ }^{19}$ Using the same distance across sparsely and densely populated areas assumes that it takes the same amount of time to cover a distance of 10 miles in rural and urban areas, which is counterfactual. Consequently, a fixed distance would inflate the number of branches in more densely populated areas while underestimating the figure for rural areas. The same approach was adopted by the Bank Policy Institute's report Some Facts about Bank Branches and LMI Customers.

${ }^{20}$ Any branches of the same bank serving a tract are treated as one unit because they are not considered competitors.
} 
the tracts that remained CRA-ineligible after the census data update. Moreover, we exclude all new tracts in the 2010 census that were not included in the 2000 census and also restrict the analysis to tracts whose boundaries were relatively unchanged. Overall, we have 73,366 observations with 69,315 observations belonging to upper-middle income (UMI) tracts with a MFI above the $80 \%$ cutoff and 4,051 observations belonging to LMI tracts with a MFI below the $80 \%$ cutoff.

Table 1 Panel A provides summary statistics on our bank data for the subsample of UMI census tracts and the subsample of LMI census tracts. It reports statistics on the number and amount of small business loans, the number of branches split by bank size, and the HHI bank concentration measure. Table 1 Panel B summarizes the demographic data including the tract population, the percentage of minority population, and the MFI. Moreover, it includes business data, specifically the number of small firms, the average trade credit (PAYDEX) score, and the proportion of firms with trade credit score higher than 70.

Table 1: Descriptive statistics for upper-middle income tracts \& lower-moderate income tracts

\begin{tabular}{|c|c|c|c|c|c|c|c|c|}
\hline \multirow[b]{3}{*}{ VARIABLES } & \multicolumn{8}{|c|}{ Panel A: Bank branch and small business loan data } \\
\hline & \multicolumn{4}{|c|}{$80 \% \leq \mathrm{MFI}(\mathrm{N}=69,315)$} & \multicolumn{4}{|c|}{$\mathrm{MFI}<80 \%(\mathrm{~N}=4,051)$} \\
\hline & mean & sd & $\min$ & $\max$ & mean & sd & $\min$ & $\max$ \\
\hline Number of small business loans & 35.25 & 33.72 & 0 & 1,146 & 24.17 & 31.72 & 0 & 1,191 \\
\hline Total amount (\$Th) of small business loans & 1,121 & 1,388 & 0 & 33,090 & 848.9 & 1,290 & 0 & 35,015 \\
\hline Branches of small banks & 2.310 & 2.751 & 0 & 48 & 1.987 & 2.339 & 0 & 29 \\
\hline Branches of large banks & 5.829 & 4.997 & 0 & 62 & 5.333 & 4.181 & 0 & 49 \\
\hline \multirow[t]{3}{*}{ HHI-tract } & 3,090 & 2,177 & 0 & 10,000 & 3,252 & 2,158 & 0 & 10,000 \\
\hline & \multicolumn{8}{|c|}{ Panel B: Demographic and business data } \\
\hline & \multicolumn{4}{|c|}{$80 \% \leq \mathrm{MFI}(\mathrm{N}=69,315)$} & \multicolumn{4}{|c|}{$\mathrm{MFI}<80 \%(\mathrm{~N}=4,051)$} \\
\hline VARIABLES & mean & sd & $\min$ & $\max$ & mean & sd & $\min$ & $\max$ \\
\hline Population & 4,314 & 1,747 & 23 & 33,041 & 4,138 & 1,747 & 37 & 16,326 \\
\hline Minority population $(\%)$ & 22.36 & 22.17 & 0 & 99.93 & 42.68 & 28.57 & 1.030 & 99.87 \\
\hline Tract MFI & 68,841 & 28,827 & 20,833 & 250,001 & 45,564 & 10,789 & 2,499 & 85,912 \\
\hline Number of small firms & 182.8 & 162.4 & 1 & 5,774 & 158.4 & 171.2 & 5 & 5,515 \\
\hline Trade credit score & 71.06 & 3.462 & 33.38 & 80.57 & 69.55 & 4.169 & 18 & 80 \\
\hline Proportion of firms with score higher than 70 & 0.753 & 0.0883 & 0 & 1 & 0.719 & 0.100 & 0 & 1 \\
\hline
\end{tabular}

A direct comparison between the two groups of tracts reveals that LMI tracts, on average, are slightly less populated and have a significantly higher proportion of minority population compared to UMI tracts. Consistent with Mills, Battisto, and Lieberman (2019), on average, LMI tracts have fewer small firms, fewer large and small bank branches, and lower bank competition (higher HHI) compared to UMI tracts. Given these statistics, it is not surprising that, on average, LMI tracts have lower numbers and amounts of small business loans and lower firm trade credit scores compared to the UMI tracts. 
Our baseline RD estimates use tract observations from Table 1 but assign greater weights to those observations close to the $80 \%$ MFI cutoff. To compare the subsample of tracts within $10 \%$ of this cutoff, Table 2 Panels A and B summarize the characteristics of tracts with a MFI between $80 \%$ and $90 \%$ to tracts with a MFI between $70 \%$ and $80 \%$. The table indicates that differences between UMI and LMI tracts close to the cutoff are mostly eliminated, allowing us to conclude that these tracts have similar demographic, business, and banking characteristics.

Table 2: Descriptive statistics for upper-middle income tracts \& lower-moderate income tracts with MFI close to the CRA threshold

\begin{tabular}{|c|c|c|c|c|c|c|c|c|}
\hline & \multicolumn{8}{|c|}{ Panel A: Bank branch and small business loan data } \\
\hline & \multicolumn{4}{|c|}{$80 \% \leq \mathrm{MFI}<90 \%(\mathrm{~N}=10,863)$} & \multicolumn{4}{|c|}{$70 \%<\mathrm{MFI}<80 \%(\mathrm{~N}=2,608)$} \\
\hline VARIABLES & mean & sd & $\min$ & $\max$ & mean & sd & $\min$ & $\max$ \\
\hline Number of small business loans & 24.68 & 23.39 & 0 & 479 & 24.93 & 34.45 & 0 & 1,191 \\
\hline Total amount ( $\$ \mathrm{Th})$ of small business loans & 825.0 & 1,116 & 0 & 20,302 & 857.3 & 1,353 & 0 & 35,015 \\
\hline Branches of small banks & 2.032 & 2.347 & 0 & 48 & 1.974 & 2.212 & 0 & 20 \\
\hline Branches of large banks & 4.929 & 4.302 & 0 & 62 & 5.258 & 4.108 & 0 & 49 \\
\hline \multirow[t]{3}{*}{$\mathrm{HHI}$} & 3,432 & 2,321 & 0 & 10,000 & 3,234 & 2,161 & 0 & 10,000 \\
\hline & \multicolumn{8}{|c|}{ Panel B: Demographic and business data } \\
\hline & \multicolumn{4}{|c|}{$80 \% \leq \mathrm{MFI}<90 \%(\mathrm{~N}=10,863)$} & \multicolumn{4}{|c|}{$70 \%<\mathrm{MFI}<80 \%(\mathrm{~N}=2,608)$} \\
\hline VARIABLES & mean & $\mathrm{sd}$ & $\min$ & $\max$ & mean & sd & $\min$ & $\max$ \\
\hline Population & 4,153 & 1,612 & 37 & 16,532 & 4,247 & 1,722 & 494 & 16,326 \\
\hline Minority population (\%) & 29.47 & 26.57 & 0 & 99.76 & 39.09 & 28.13 & 1.040 & 99.67 \\
\hline Tract MFI & 47,805 & 11,267 & 20,833 & 95,777 & 48,726 & 10,303 & 24,274 & 85,912 \\
\hline Number of small firms & 154.0 & 127.9 & 1 & 4,024 & 161.4 & 183.4 & 8 & 5,515 \\
\hline Trade credit score & 70.37 & 3.808 & 33.38 & 80.19 & 69.76 & 4.036 & 18 & 79.34 \\
\hline Proportion of firms with score higher than 70 & 0.734 & 0.0965 & 0 & 1 & 0.726 & 0.0966 & 0 & 1 \\
\hline
\end{tabular}

As a robustness exercise, we estimate the effects of CRA eligibility using a separate sample of matched tracts. At first glance, the use of a matched sample in RD design seems unnecessary. Heckman, LaLonde, and Smith (1999) argue that regression discontinuity estimators constitute a special case of selection on observables, and thus, the RD estimator is a limit form of matching. Indeed, as we observed above, the heterogeneity of observable tract characteristics is largely eliminated for tracts with MFI ratios close to the CRA cutoff. Nonetheless, tracts from different states may be subject to different regulatory and legal frameworks, such as branch banking policies. Since these disparities could affect the supply of bank credit, we will perform an alternative estimation exercise using a matched sample that accounts for unobservable state-induced heterogeneity. 
Specifically, for every tract that becomes eligible for CRA regulation, we find a matched tract that remained ineligible and that is located in the same MSA or in the same state if the tract is not in an MSA. Matching is performed based on the tracts having similar population, proportion of minority population, MFI, number of small firms, number of large bank branches, and number of small bank branches. Matching uses a nearest neighbor approach with distances that are a weighted function of the above covariates. Weights are derived from the Mahalanobis method, which is based on the inverse of the covariates' variancecovariance matrix. Table 3 Panels A and B summarize the characteristics of the same-state matched tractyear observations split between UMI and LMI tracts. ${ }^{21}$

Table 3: Descriptive statistics for upper-middle income tracts \& lower-moderate income matched tracts

\begin{tabular}{|c|c|c|c|c|c|c|c|c|}
\hline & \multicolumn{8}{|c|}{ Panel A: Bank branch and small business loan data } \\
\hline & \multicolumn{4}{|c|}{$80 \% \leq$ MFI $(\mathrm{N}=10,274)$} & \multicolumn{4}{|c|}{$\mathrm{MFI}<80 \%(\mathrm{~N}=3,974)$} \\
\hline VARIABLES & mean & sd & $\min$ & $\max$ & mean & sd & $\min$ & $\max$ \\
\hline Number of small business loans & 25.59 & 29.66 & 0 & 1,146 & 24.07 & 31.85 & 0 & 1,191 \\
\hline Total amount (\$Th) of small business loans & 862.2 & 1,214 & 0 & 32,205 & 847.1 & 1,290 & 0 & 35,015 \\
\hline Branches of small banks & 2.147 & 2.441 & 0 & 32 & 1.986 & 2.346 & 0 & 29 \\
\hline Branches of large banks & 5.583 & 4.268 & 0 & 50 & 5.350 & 4.189 & 0 & 49 \\
\hline \multirow[t]{3}{*}{ HHI } & 3,088 & 2,044 & 0 & 10,000 & 3,248 & 2,160 & 0 & 10,000 \\
\hline & \multicolumn{8}{|c|}{ Panel B: Demographic and business data } \\
\hline & \multicolumn{4}{|c|}{$80 \% \leq$ MFI $(\mathrm{N}=10,274)$} & \multicolumn{4}{|c|}{$\mathrm{MFI}<80 \%(\mathrm{~N}=3,974)$} \\
\hline VARIABLES & mean & sd & $\min$ & $\max$ & mean & sd & $\min$ & $\max$ \\
\hline Population & 4,093 & 1,534 & 91 & 15,955 & 4,138 & 1,751 & 37 & 16,326 \\
\hline Minority population $(\%)$ & 33.26 & 26.84 & 0.440 & 99.77 & 42.94 & 28.58 & 1.030 & 99.87 \\
\hline Tract MFI & 51,150 & 13,629 & 20,833 & 200,001 & 45,322 & 10,668 & 2,499 & 85,912 \\
\hline Number of small firms & 158.3 & 166.6 & 5 & 5,774 & 157.9 & 171.8 & 5 & 5,515 \\
\hline Trade credit score & 70.09 & 3.897 & 33.38 & 80.19 & 69.55 & 4.179 & 18 & 80 \\
\hline Proportion of firms with score higher than 70 & 0.725 & 0.0987 & 0 & 1 & 0.719 & 0.101 & 0 & 1 \\
\hline
\end{tabular}

\section{Empirical results}

\subsection{CRA regulation and bank lending to small firms}

The fundamental assumption of this study's fuzzy RD design is that the probability of a substantial increase in bank lending to small firms is greater in census tracts that become CRA-eligible compared to census tracts that remain ineligible. We begin the empirical investigation by providing explicit evidence in support

\footnotetext{
${ }^{21}$ The number of LMI and UMI tracts differ in Table 3, since in 2011, all tracts were ineligible UMI tracts, while 3,974 of these tracts became eligible LMI tracts in 2012.
} 
of this assumption. In particular, we define a substantial increase in a census tract's loans to small firms as an increase of at least $20 \%$ either in the number or in the total amount of these loans. ${ }^{22}$

Table 4 columns (1) and (2) present the estimated discontinuity jump in the probability of a substantial increase in loans to small firms, $\hat{\tau}_{T}=\mu_{T^{-}}-\mu_{T^{+}}$, for the unmatched and the matched samples, respectively. These estimations use a set of covariates $\mathbb{Z}_{i}$ that includes the census tract's population, the population's proportion of minorities, the MFI, and the number of small and large bank branches within the tract's search area. The estimates indicate that CRA eligibility leads to approximately $25 \%$ and $34 \%$ higher probabilities of a substantial increase in loans for the unmatched and matched samples, respectively. These results are consistent with prior evidence that the CRA promotes small business lending. Ding, Lee, and Bostic (2018) show that the CRA leads to an increase in the number of loan originations, Agarwal, Benmelech, Bergman, and Seru (2012) find that, in the six quarters surrounding a CRA exam, lending by banks is elevated on average by 5\%, and Kim, Lee, and Earle (2021) find a 3\% to 4\% increase in the number of small business loans and a $6 \%$ to $10 \%$ increase in the dollar loan amount in tracts that become CRA eligible.

Table 4 columns (3) to (6) also present estimates of the probability of a substantial increase in loans due to CRA eligibility for subsamples based on a census tract's level of bank concentration. We follow Department of Justice (DoJ) guidelines and define low bank competition tracts as having an HHI greater than 1800 and high bank competition tracts as having an HHI less than $1800 .{ }^{23}$ For the unmatched samples, CRA eligibility leads to an approximately $27 \%$ higher probability of a substantial increase in loans in low competition tracts and a $23 \%$ higher probability in high competition tracts. For the matched sample, CRA eligibility results in an approximately $36 \%$ higher probability of a loan growth increase in low competition tracts and a $32 \%$ probability in high competition tracts. In summary, the evidence indicates a significant rise in the probability of a substantial increase in bank lending to small firms in census tracts that become CRA eligible, and the rise occurs in newly eligible tracts with both low and high bank competition.

\footnotetext{
${ }^{22}$ The median growth in the entire population of tracts is $1.3 \%$ in the number of loans and $0.06 \%$ in the amount. The chances of observing at least $20 \%$ annual growth in the number of small firm loans is $25 \%$. We have tested other thresholds of loan growth in the range between $15 \%$ to $25 \%$ and all reported results remain statistically significant.

${ }^{23}$ More details are available at: https://www.justice.gov/atr/bank-merger-competitive-review-introduction-and-overview1995.
} 
Table 4: CRA eligibility and small firm loan growth

\begin{tabular}{|c|c|c|c|c|c|c|}
\hline & \multicolumn{2}{|c|}{ All tracts } & \multicolumn{2}{|c|}{ Low bank competition tracts } & \multicolumn{2}{|c|}{ High bank competition tracts } \\
\hline VARIABLES & (1) & (2) & (3) & (4) & (5) & (6) \\
\hline \multirow[t]{2}{*}{ Conventional } & $0.246 * * *$ & $0.341 * * *$ & $0.267 * * *$ & $0.362 * * *$ & $0.228 * * *$ & $0.318 * * *$ \\
\hline & $(0.0197)$ & $(0.0212)$ & $(0.0215)$ & $(0.0235)$ & $(0.0433)$ & $(0.0450)$ \\
\hline \multirow[t]{2}{*}{ Bias-corrected } & $0.250 * * *$ & $0.344 * * *$ & $0.272 * * *$ & $0.367 * * *$ & $0.236 * * *$ & $0.323 * * *$ \\
\hline & $(0.0197)$ & $(0.0212)$ & $(0.0215)$ & $(0.0235)$ & $(0.0433)$ & $(0.0450)$ \\
\hline \multirow[t]{2}{*}{ Robust } & $0.250 * * *$ & $0.344 * * *$ & $0.272 * * *$ & $0.367 * * *$ & $0.236 * * *$ & $0.323 * * *$ \\
\hline & $(0.0230)$ & $(0.0247)$ & $(0.0249)$ & $(0.0270)$ & $(0.0510)$ & $(0.0526)$ \\
\hline Observations & 73366 & 14248 & 49461 & 10292 & 21021 & 3550 \\
\hline Robust $95 \%$ CI & {$[.205 ; .295]$} & {$[.296 ; .393]$} & {$[.223 ; .32]$} & {$[.315 ; .42]$} & {$[.136 ; .336]$} & {$[.22 ; .426]$} \\
\hline Kernel Type & Epanechnikov & Epanechnikov & Epanechnikov & Epanechnikov & Epanechnikov & Epanechnikov \\
\hline BW Type & mserd & mserd & mserd & mserd & mserd & mserd \\
\hline Sample & Total & Matched & Total & Matched & Total & Matched \\
\hline Order Loc.Poly.(p) & 1.000 & 1.000 & 1.000 & 1.000 & 1.000 & 1.000 \\
\hline $\operatorname{Order} \operatorname{Bias}(\mathrm{q})$ & 2.000 & 2.000 & 2.000 & 2.000 & 2.000 & 2.000 \\
\hline BW Loc.Poly.(h) & 11.306 & 10.124 & 12.711 & 11.104 & 11.465 & 10.745 \\
\hline BW Bias (b) & 19.342 & 17.823 & 22.673 & 20.731 & 19.008 & 18.318 \\
\hline
\end{tabular}

Note: The outcome variables are the probabilities of an increase of at least $20 \%$ in either the number or the total amount of bank loans made to small firms. Covariates include the tract's population, the proportion of minority populations, the MFI, and the number of small and large bank branches. Bank competition is measured by HHI. Conventional estimator of RD is based on the first order (linear) polynomial estimators in (3.4) and (3.5). (Robust) Bias-corrected is the first order polynomial RD estimator in (3.6). Reported bandwidths are percentage points of the MFI ratio. Standard errors in parentheses. Significance levels are $* * * 1 \%, * * 5 \%$, and $* 10 \%$.

\subsection{CRA regulation and small firm trade credit}

The CRA-induced increase in bank lending documented in the previous section does not automatically imply that small firms will reduce their reliance on trade credit. We now address this issue by providing empirical evidence that when a census tract becomes CRA eligible, small firms' average PAYDEX score rises. The higher PAYDEX score, which indicates more rapid payments to vendors and suppliers, is consistent with small firms substituting lower-cost bank credit for higher-cost trade credit.

As a preliminary analysis, we begin by plotting the PAYDEX score distribution one year after potential CRA eligibility relative to the ratio of the census tract's MFI ratio using the evenly spaced method to select the number of bins. The left RD plot in Figure 1 reveals that there is a discontinuous jump at the $80 \%$ MFI cutoff. In particular, the small firms located in census tracts with an MFI ratio lower than $80 \%$ have an average PAYDEX score, one year after the tract's eligibility, significantly higher than the average score of small firms located in census tracts with an MFI ratio higher than $80 \%$. Moreover, the lower value of the 95\% confidence interval for the sample mean of the PAYDEX score within the bin close to, but below, the cutoff is higher than the upper value of the $95 \%$ confidence interval for the sample mean of the PAYDEX 
score within the bin close to, but above, the cutoff, suggesting that the jump is statistically significant at the $5 \%$ level. In addition to the discontinuity at the cutoff, note that the plot has an upward trend indicating that small firms located in census tracts with higher MFI ratios tend to have higher PAYDEX scores. Similar conclusions are drawn by looking at the rightmost plot in Figure 1, which gives the RD plot of the proportion of firms with a PAYDEX score of more than 70.
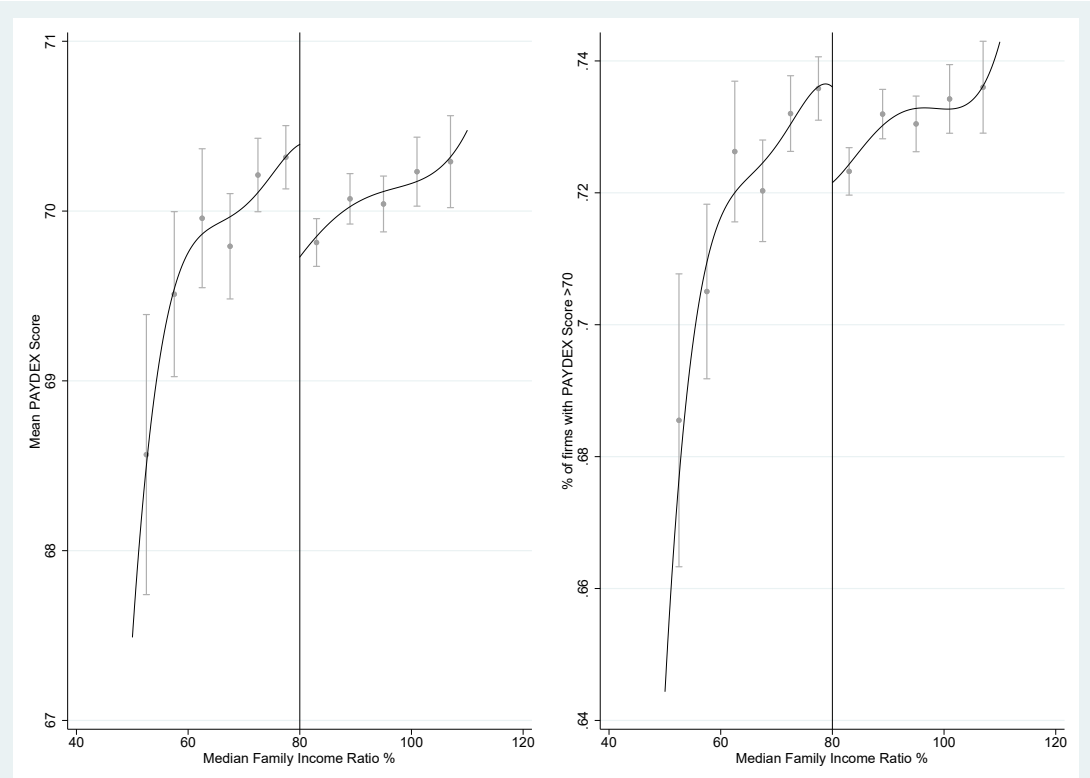

Figure 1: The trade credit score discontinuity at the cutoff point of $80 \%$ in the MFI ratio

We now turn to estimating the effect of CRA eligibility, $\hat{\tau}_{Y}$ in equation (3.7), on small firms' average PAYDEX score one year after their census tract's eligibility. The estimation again includes covariates for the census tract's population, the population's proportion of minorities, the MFI, and the number of small and large bank branches within the search area. The results in Table 5 Panel A show that there is a statistically significant increase in the average PAYDEX score of small firms in the year following CRA eligibility. For example, the bias corrected local linear estimate varies from 1.31 to 1.40 points for the full sample and 1.70 to 1.72 points for the matched sample. The magnitude of the effect is equal to half of the score's standard deviation. Based on how PAYDEX is calculated, a 1 point improvement at the sample average PAYDEX of 70 implies a 1.5-day shorter bill payment period. Thus, the bias-corrected estimates imply that CRA eligibility leads to a reduction in the average time that small firms use trade credit of 2.0 to 2.6 days. 
Table 5: Effect of CRA regulation on firms' trade credit score

\begin{tabular}{|c|c|c|c|c|}
\hline & \multicolumn{4}{|c|}{ Panel A: PAYDEX score } \\
\hline VARIABLES & (1) & (2) & (3) & (4) \\
\hline \multirow[t]{2}{*}{ Conventional } & $1.413^{* *}$ & $1.434 * *$ & $1.683 * * *$ & $1.772 * * *$ \\
\hline & $(0.583)$ & $(0.568)$ & $(0.484)$ & $(0.495)$ \\
\hline \multirow[t]{2}{*}{ Bias-corrected } & $1.308 * *$ & $1.400 * *$ & $1.698 * * *$ & $1.719 * * *$ \\
\hline & $(0.583)$ & $(0.568)$ & $(0.484)$ & $(0.495)$ \\
\hline \multirow[t]{2}{*}{ Robust } & $1.308^{*}$ & $1.400 * *$ & $1.698 * * *$ & $1.719 * * *$ \\
\hline & $(0.676)$ & $(0.635)$ & $(0.559)$ & $(0.560)$ \\
\hline Observations & 73366 & 73366 & 14248 & 14248 \\
\hline Robust $95 \%$ CI & {$[-.018 ; 2.633]$} & {$[.155 ; 2.645]$} & {$[.602 ; 2.794]$} & {$[.622 ; 2.816]$} \\
\hline Kernel Type & Epanechnikov & Uniform & Epanechnikov & Uniform \\
\hline BW Type & mserd & msecomb1 & mserd & msecomb1 \\
\hline Sample & Total & Total & Matched & Matched \\
\hline Order Loc.Poly.(p) & 1.000 & 1.000 & 1.000 & 1.000 \\
\hline $\operatorname{Order} \operatorname{Bias}(\mathrm{q})$ & 2.000 & 2.000 & 2.000 & 2.000 \\
\hline BW Loc.Poly.(h) & 10.950 & 10.256 & 10.586 & 9.257 \\
\hline \multirow[t]{2}{*}{ BW Bias (b) } & 19.221 & 21.994 & 19.065 & 19.138 \\
\hline & \multicolumn{4}{|c|}{ Panel B: Proportion of firms with PAYDEX $>70$} \\
\hline VARIABLES & $(1)$ & $(2)$ & (3) & (4) \\
\hline \multirow[t]{2}{*}{ Conventional } & $0.0303 * *$ & $0.0347 * *$ & $0.0357 * * *$ & $0.0389 * * *$ \\
\hline & $(0.0152)$ & $(0.0145)$ & $(0.0127)$ & $(0.0129)$ \\
\hline \multirow[t]{2}{*}{ Bias-corrected } & $0.0275^{*}$ & $0.0331 * *$ & $0.0353 * * *$ & $0.0387 * * *$ \\
\hline & $(0.0152)$ & $(0.0145)$ & $(0.0127)$ & $(0.0129)$ \\
\hline \multirow[t]{2}{*}{ Robust } & 0.0275 & $0.0331 * *$ & $0.0353 * *$ & $0.0387 * * *$ \\
\hline & $(0.0176)$ & $(0.0165)$ & $(0.0147)$ & $(0.0144)$ \\
\hline Observations & 73366 & 73366 & 14248 & 14248 \\
\hline Robust $95 \%$ CI & {$[-.007 ; .062]$} & {$[.001 ; .066]$} & {$[.006 ; .064]$} & {$[.01 ; .067]$} \\
\hline Kernel Type & Epanechnikov & Uniform & Epanechnikov & Uniform \\
\hline BW Type & mserd & msecomb1 & mserd & msecomb1 \\
\hline Sample & Total & Total & Matched & Matched \\
\hline Order Loc.Poly.(p) & 1.000 & 1.000 & 1.000 & 1.000 \\
\hline $\operatorname{Order} \operatorname{Bias}(\mathrm{q})$ & 2.000 & 2.000 & 2.000 & 2.000 \\
\hline BW Loc.Poly.(h) & 11.053 & 10.576 & 9.990 & 8.828 \\
\hline BW Bias (b) & 19.586 & 20.734 & 18.010 & 19.070 \\
\hline
\end{tabular}

Note: The outcome variables are the one-year forward tract-level average trade credit score of small firms (Panel A) and the proportion of firms with a trade credit score of more than 70 (Panel B). Covariates include the tract's population, the proportion of minority populations, the MFI, and the number of small and large bank branches. Conventional estimator of RD is based on the first order (linear) polynomial estimators in (3.4) and (3.5). (Robust) Biascorrected is the first order polynomial fuzzy RD estimator in (3.7). Reported bandwidths are percentage points of the MFI ratio. Standard errors in parentheses. Significance levels are $* * * 1 \%, * 5 \%$, and $* 10 \%$. 
Table 5 Panel B provides evidence similar to that of Panel A by showing that in newly CRA-eligible census tracts, there is an increase in the proportion of small firms having a PAYDEX score exceeding 70. The effect measured by the bias-corrected local linear estimate of $\hat{\tau}_{Y}$ in equation (3.7) varies from $2.75 \%$ to $3.87 \%$. This increase is economically significant when compared to the approximately $71.6 \%$ proportion of firms in LMI tracts that have a PAYDEX exceeding 70 in the year prior eligibility.

In summary, this section's evidence is consistent with small firms in newly CRA-eligible census tracts using bank loans to reduce their trade credit. Since trade credit is more expensive relative to institutional finance such as bank loans (Petersen and Rajan (1997)), our results suggest that small firms are able to reduce their overall financing costs when their census tract becomes CRA-eligible.

\subsection{CRA regulation, bank competition, and small firm trade credit}
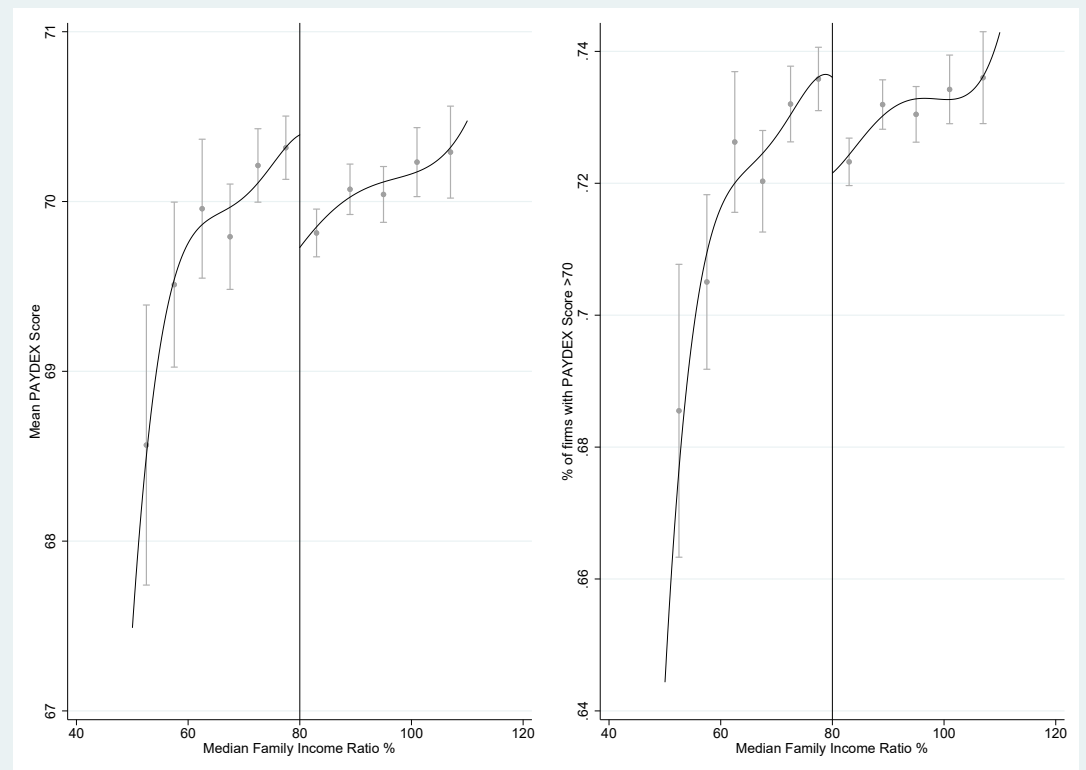

Figure 2: The trade credit score discontinuity and bank competition

The effect of CRA regulation on trade credit documented above applies to the average tract in our sample. In this section, guided by the predictions of our theoretical model, we examine this effect conditional on bank competition as measured by the HHI of the tract's search area. We begin by plotting the PAYDEX score distribution one year following potential CRA eligibility versus the census tract's MFI ratio for low 
and high bank competition tracts. For low competition tracts having an HHI above 1800, the top left RD plot in Figure 2 indicates that there is a discontinuous jump in the average PAYDEX score at the $80 \%$ MFI cutoff for CRA eligibility. The 95\% confidence interval's lower bound for the average PAYDEX score close to, but below, the cutoff is higher than the upper bound of the $95 \%$ confidence interval for the average PAYDEX score close to, but above, the cutoff, suggesting that the jump is statistically significant at the 5\% level. Similarly, the bottom left RD plot in Figure 2 shows that in low competition tracts there is also a statistically significant jump in the proportion of firms with a PAYDEX score exceeding 70 at the $80 \%$ MFI cutoff.

The right RD plots in Figure 2 show the distribution of the average PAYDEX score (top panel) and the proportion of firms with PAYDEX exceeding 70 (bottom panel) for census tracts with high bank competition having an HHI below 1800. While these top and bottom right plots reveal a discontinuous jump at the $80 \%$ MFI cutoff for CRA eligibility, the discontinuity does not appear statistically significant because the two confidence intervals, just below and just above the cutoff, overlap.

Table 6 provides more formal estimates of the effects of CRA eligibility on PAYDEX scores for unmatched and matched samples split between low bank competition and high bank competition tracts. Its results reinforce the graphical findings in Figure 2. Columns (1) and (2) of Table 6 Panel A show that in tracts with low bank competition (HHI > 1800), CRA eligibility has a strong positive effect on the average trade credit score one year after the change in eligibility status. As a robustness check, columns (3) and (4) of Table 6 Panel A present results using an alternative measure of low bank competition, namely census tracts where the total number of bank branches is below the overall sample median. These results show that in tracts with a relatively low number of bank branches, CRA eligibility has a strong positive effect on the average trade credit score one year after the change in eligibility status.

Turning to tracts with high bank competition, Table 6 Panel A columns (5) and (6) provide results for tracts with an HHI below 1800 while columns (7) and (8) present results for tracts with an above median number of bank branches. Overall, these results indicate that the effect of new CRA eligibility on small firms' trade credit scores is insignificant or statistically weaker than the effect on small firm trade credit found for low competition tracts. Similarly, Table 6 Panel B columns (1) and (4) confirm that in markets 


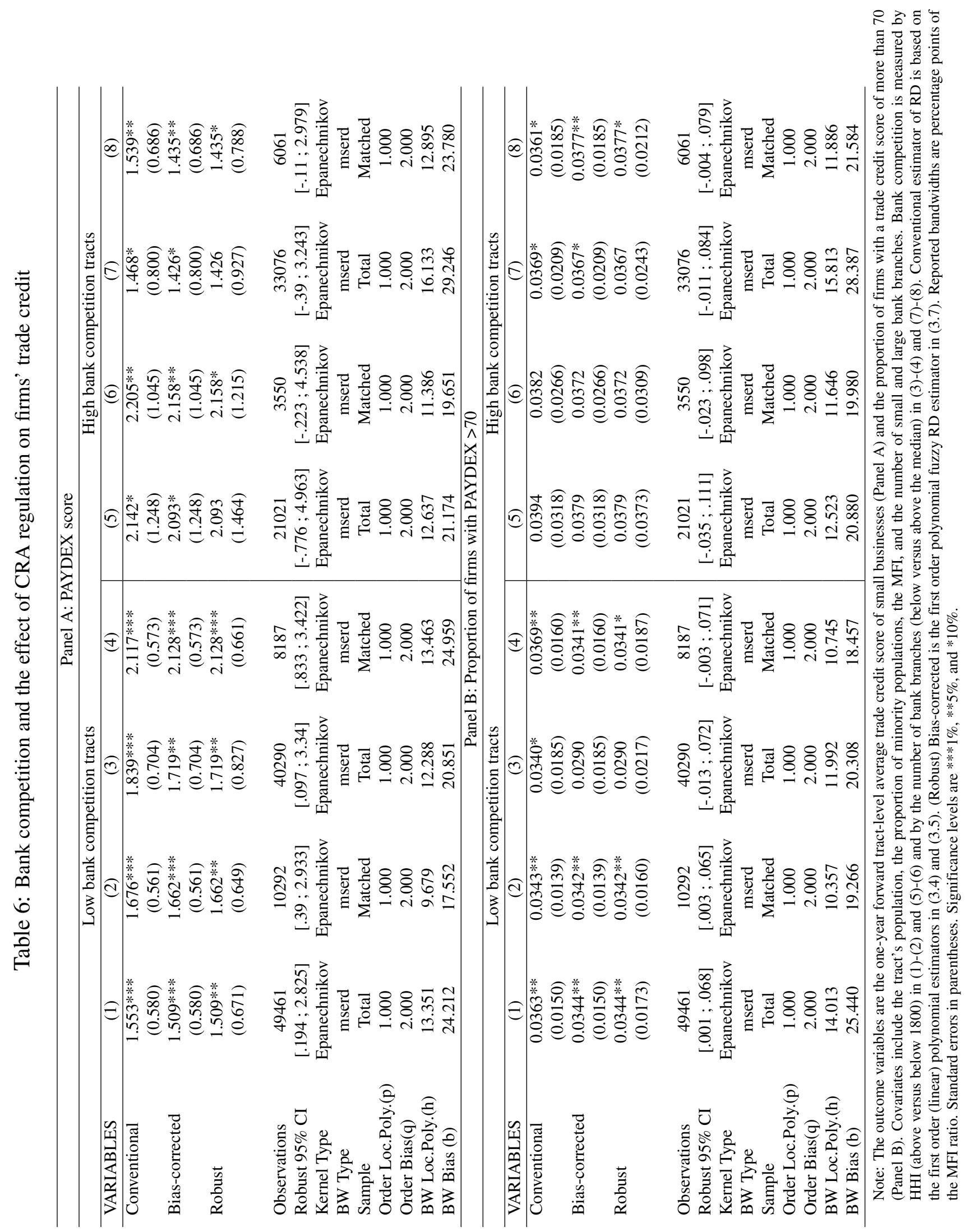


with low bank competition, CRA eligibility increases the proportion of firms with a trade credit score of more than 70, while columns (5) and (8) show that the effect of CRA regulation on the proportion of firms with a trade credit score of more than 70 is not statistically significant in tracts with high bank competition.

Taken together, these results are consistent with the predictions of our theoretical model. Small firms in high bank competition tracts are likely to receive bank loans even without the added stimulus from CRA regulations, so the CRA appears to have less impact on their use of trade credit. ${ }^{24}$ In contrast, small firms located in tracts with low bank competition are more likely to be financially constrained and thus more dependent on trade credit. When their tracts become CRA-eligible, these firms are more likely to use the CRA-induced bank loans to substitute for more expensive trade credit. In summary, our findings indicate that the impact of CRA regulation on small firms' financing costs is moderated by the degree of local bank competition.

\subsection{Comparing small firms with heterogeneous trade credit dependence}

Some industries tend to use trade credit more than others. Petersen and Rajan (1997) find that among small firms, those in manufacturing and wholesale trade sectors display a higher dependence on trade credit compared to firms in services and retail trade sectors. In this section, we analyze whether CRA-induced bank lending impacts trade credit differently across these two groups of sectors. In particular, firms that are ex-ante more (less) dependent on trade credit may be more (less) likely to substitute bank loans for trade credit. Based on this, we calculate separately the average PAYDEX score of firms belonging to trade credit-dependent sectors and the average PAYDEX score of firms not belonging to trade credit-dependent sectors. Effectively, we use the heterogeneity in trade credit dependence to run a treatment versus a placebo robustness test of our earlier findings.

We begin by plotting the PAYDEX score of firms in trade credit-dependent sectors for low and high bank competition tracts. Specifically, the left top (bottom) RD plots in Figure 3 confirm that there is a

\footnotetext{
${ }^{24} \mathrm{~A}$ univariate t-test of means shows that the average PAYDEX score prior to the change in CRA eligibility is higher among high bank competition tracts. Specifically, the mean PAYDEX score in high bank competition tracts is 0.23 greater than that in low bank competition tracts, which is equivalent to five standard deviations, a statistically significant difference. Similarly, the proportion of firms with a PAYDEX score exceeding 70 in high bank competition tracts is 0.65 percentage points greater than that in low bank competition tracts, which is equivalent to almost six standard deviations, a statistically significant difference.
} 

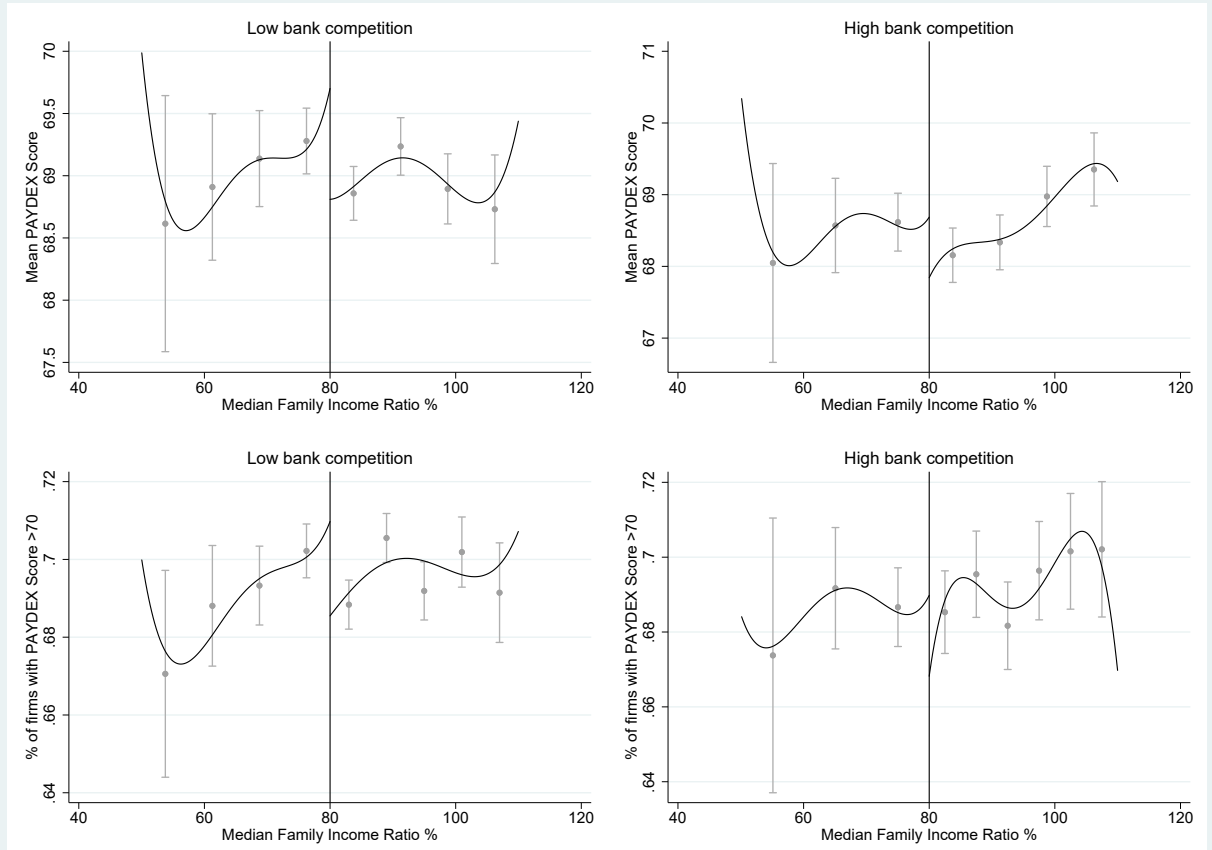

Figure 3: The trade credit score discontinuity in trade credit-dependent sectors
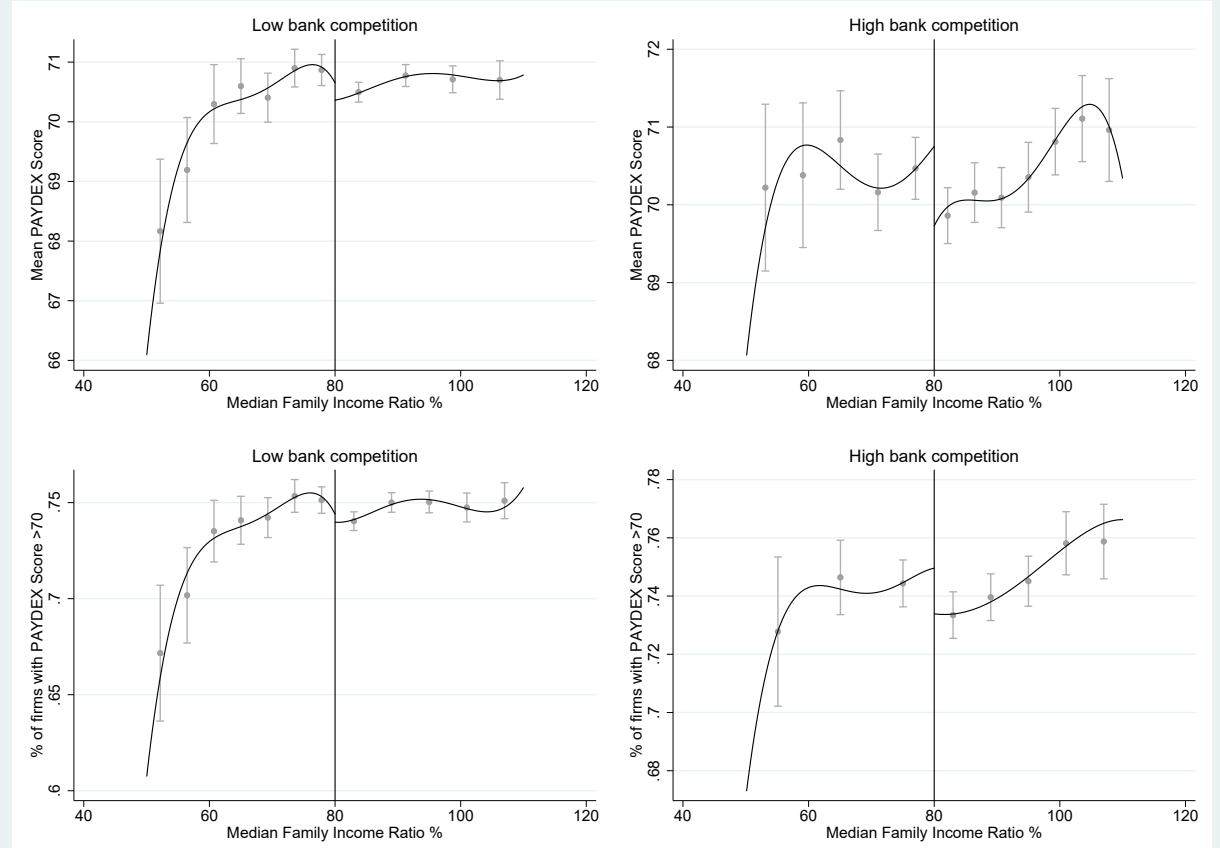

Figure 4: The trade credit score discontinuity in trade credit-independent sectors 
discontinuity in the average PAYDEX score (the proportion of firms with score higher than 70) among firms in trade credit-dependent sectors in low bank competition tracts. Moreover, the right top (bottom) RD plots in Figure 3 reveal that the discontinuity in the average PAYDEX score (the proportion of firms with score higher than 70) among firms in trade credit-dependent sectors vanishes in high bank competition tracts. Importantly, the RD plots in Figure 4 reveal no statistically significant discontinuity in the average PAYDEX score and in the proportion of firms with scores higher than 70 among firms in trade credit-independent sectors, irrespective of local bank competition. Taken together, this plot-based evidence indicates a link between trade credit dependence and the documented effect of CRA-induced bank lending on firms' trade credit scores.

Table 7 presents more formal results on the effects of CRA-induced bank lending on trade credit used by small firms in trade credit-dependent sectors. In particular, it provides strong evidence that only in low competition census tracts do firms in trade credit-dependent sectors substitute CRA-generated loans for trade credit. Specifically, Table 7 Panel A columns (1) to (2) show that there is statistically and economically significant increase in PAYDEX scores among trade credit-dependent firms operating in low bank competition tracts having an HHI above 1800. The estimated improvement in their average PAYDEX score is up to 2.72 points, implying a 4-day shorter bill payment period. When low competition tracts are defined as having below-median numbers of branches, Table 7 Panel A columns (3) to (4) indicate an even greater improvement in PAYDEX, implying a 5- to 6- day shorter payment period. In contrast, Panel A columns (5) to (8) show no statistically significant evidence of a decline in the use of trade credit for firms in high bank competition tracts.

Similarly, Table 7 Panel B columns (1) to (4) show that CRA-induced bank lending raises the proportion of trade credit-dependent firms with a PAYDEX exceeding 70 for trade credit-dependent firms operating in low bank competition tracts. The estimated effect is statistically and economically significant and ranges from 5.50 to $7.55 \%$. However, consistent with our model's prediction and our earlier empirical evidence, Panel B columns (5) to (8) indicate no statistically significant effect on trade credit when these firms operate in high bank competition tracts. 


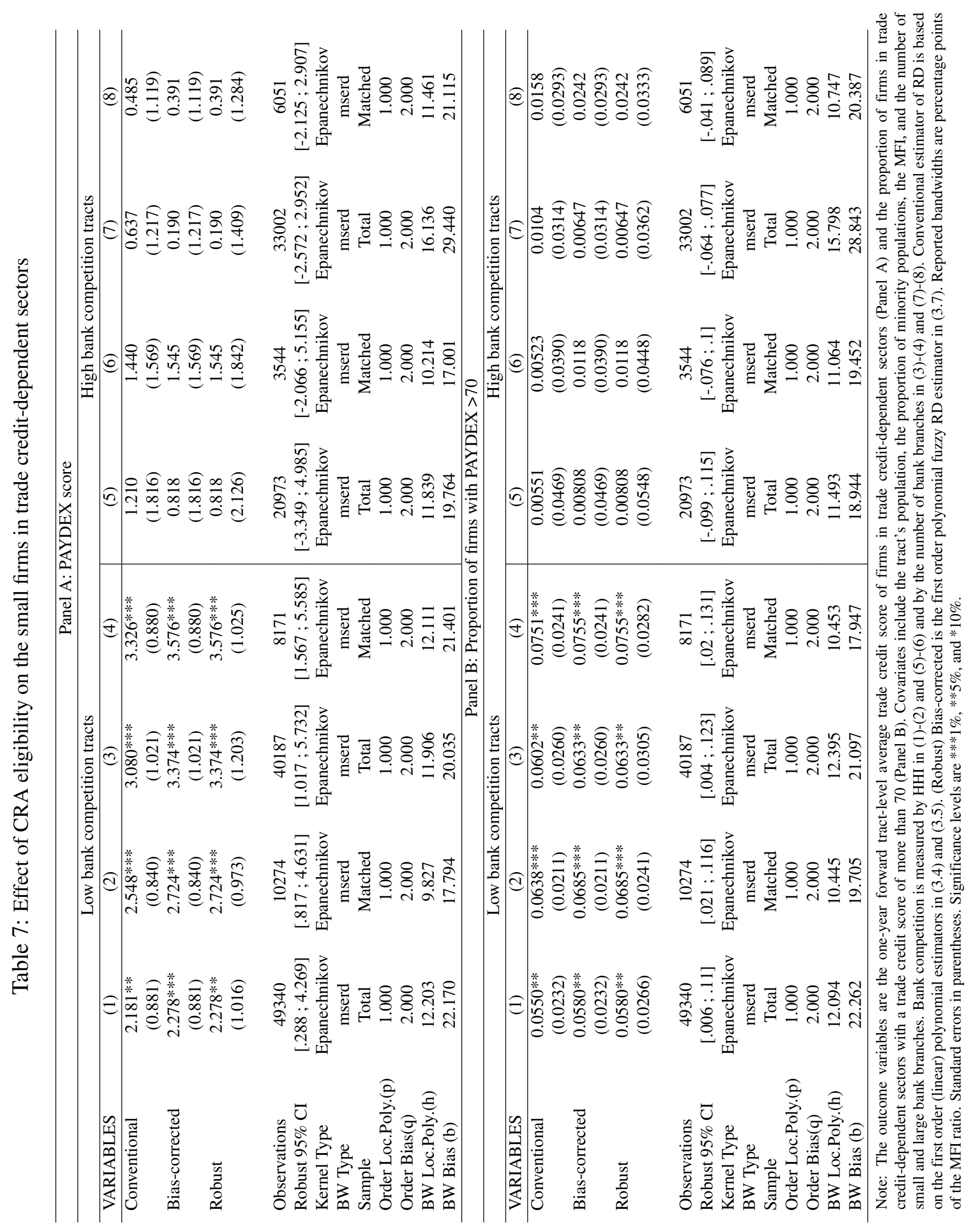




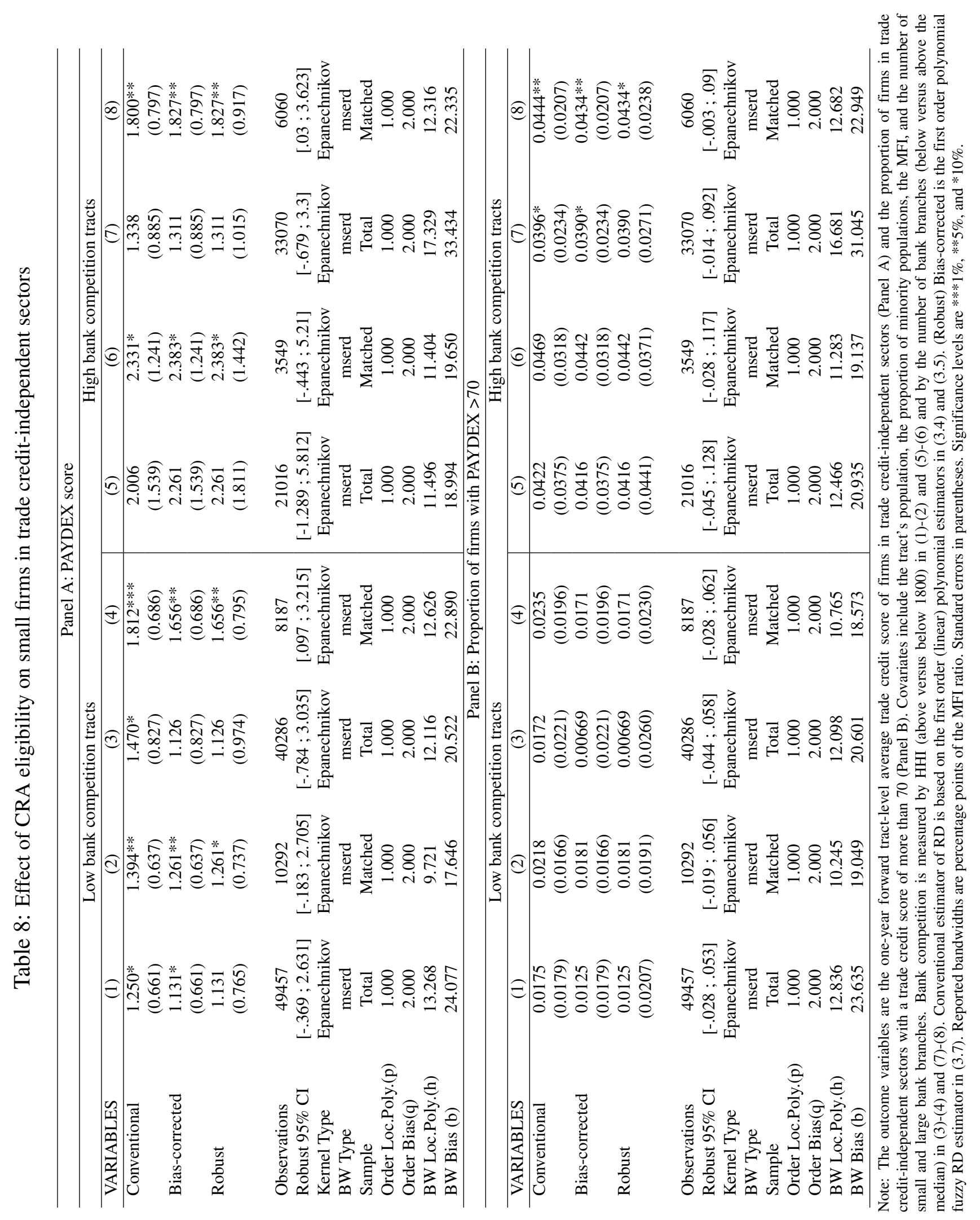


Table 8 repeats the estimation exercises presented in Table 7 but uses data on the subsample of small firms operating in trade credit-independent sectors rather than in trade credit-dependent sectors. Interestingly, it finds that CRA-induced bank lending has statistically weak or insignificant effects on reducing these firms' use of trade credit. Taken together, the results in Tables 7 and 8 show that CRA-induced bank lending reduces small firms' reliance on trade credit mainly when firms operate in industries that traditionally depend on trade credit and only when these firms are located in areas where bank competition is low. These results are consistent with our model's intuition that high-cost trade credit is more likely to be replaced with lower-cost, CRA-induced bank loans when firms were previously dependent on trade credit, in part because they previously faced financial constraints due to low bank competition.

\subsection{Falsification analysis}

A main advantage of our RD design is that the mechanism by which CRA eligibility is assigned is based on whether a census tract's MFI ratio is below a given eligibility threshold. Assuming that a tract's MFI ratio is not manipulated by agents such as the tract's individual small firms or banks, then variation in CRA eligibility when the MFI ratio is near the threshold is random as in a randomized experiment (Lee and Lemieux (2010)). Given the objective determination of this MFI-based assignment variable, a continuity assumption of the regression function near the cutoff threshold ensures the validity of the RD design. Although the continuity assumption cannot be directly tested, there are empirical tests that provide indirect evidence of its validity. Following Cattaneo, Idrobo, and Titiunik (2019), we consider three validation exercises based on (i) the insignificant eligibility effect on pretreatment covariates (placebo outcomes), (ii) the eligibility effect observed at artificial cutoff values (placebo cutoffs) and (iii) the exclusion of observations too close to the cutoff (donut-hole analysis).

Specifically, the first test notes that CRA eligibility should not be linked to any predetermined characteristic of a census tract. Since the eligibility effect on predetermined covariates is zero by construction, consistent evidence of covariates' discontinuity would raise questions about the validity of the RD continuity assumption. For example, if tracts display significant differences at the cutoff with respect to their population or to the number of small firms, that could indicate a discontinuity in the demand for bank loans, 
which could provide an alternative explanation of the findings. Similarly, if tracts display significant differences at the cutoff with respect to the number of bank branches, that would indicate a discontinuity in access to bank loans. Therefore, we examine the significance of potential discontinuity jumps at the cutoff for the model covariates, namely, the tract's population, number of small firms, number of small bank branches and number of large bank branches. The p-values of the CRA eligibility effect on the covariates in Table 9 columns (1) to (4) provide no evidence at a 5\% level of significance that tracts display any discontinuity jumps near the cutoff with respect to their size, the number of small firms, and the number of small and large bank branches.

Table 9: Continuity-based analysis for covariates

\begin{tabular}{lcccc}
\hline VARIABLES & $\begin{array}{c}(1) \\
\text { Population }\end{array}$ & $\begin{array}{c}(2) \\
\text { No. of small firms }\end{array}$ & $\begin{array}{c}(3) \\
\text { No. of small banks }\end{array}$ & No. of large banks \\
\hline Conventional & $\mathrm{p}=0.0484$ & $\mathrm{p}=0.174$ & $\mathrm{p}=0.384$ & $\mathrm{p}=0.457$ \\
Bias-corrected & $\mathrm{p}=0.0598$ & $\mathrm{p}=0.179$ & $\mathrm{p}=0.382$ & $\mathrm{p}=0.394$ \\
Robust & $\mathrm{p}=0.0708$ & $\mathrm{p}=0.204$ & $\mathrm{p}=0.408$ & $\mathrm{p}=0.412$ \\
& & & & \\
Observations & 73366 & 73366 & 73366 & 73366 \\
Kernel Type & Epanechnikov & Epanechnikov & Epanechnikov & Epanechnikov \\
BW Type & cerrd & cerrd & cerrd & cerrd \\
Order Loc.Poly.(p) & 1.000 & 1.000 & 1.000 & 1.000 \\
Order Bias(q) & 2.000 & 2.000 & 2.000 & 2.000 \\
BW Loc.Poly.(h) & 6.384 & 6.964 & 6.428 & 4.606 \\
BW Bias (b) & 20.408 & 16.948 & 17.651 & 14.362 \\
\hline
\end{tabular}

Note: Conventional estimator p-value is based on the first order (linear) polynomial estimators in (3.4) and (3.5), and (Robust) Bias-corrected p-value is based on the first order polynomial RD estimator in (3.6) with outcome variables the covariates of the tract's population, the proportion of minority populations, and the number of small and large bank branches. Reported bandwidths are percentage points of the MFI ratio.

Our second falsification exercise tests whether there are significant effects at placebo cutoff values. Evidence of discontinuity at MFI ratios away from the actual CRA cutoff would imply that CRA regulatory eligibility is not the only "treatment" effect, casting doubt on our RD design. In the placebo cutoff test, we perform the RD model estimation but replace the MFI ratio's true cutoff value of $80 \%$ with placebo cutoff ratios of $70 \%$ and $90 \%$ where CRA eligibility does not change. In Table 10 columns (1) and (4), the estimated effects at the placebo cutoff points on the probabilities of an unexpected increase in bank loans to small firms are not, in general, statistically significant. Similarly, the estimated effects at the placebo cutoff points on the average PAYDEX trade credit scores, columns (2) and (5), and on the proportions of firms with a PAYDEX score exceeding 70, columns (3) and (6), are not statistically significant. We can therefore 
Table 10: Placebo cutoff

\begin{tabular}{|c|c|c|c|c|c|c|}
\hline \multirow{3}{*}{ VARIABLES } & \multicolumn{3}{|c|}{ Cutoff $70 \%$} & \multicolumn{3}{|c|}{ Cutoff $90 \%$} \\
\hline & (1) & (2) & (3) & (4) & (5) & (6) \\
\hline & Bank loans & PAYDEX score & $\%$ PAYDEX $>70$ & Bank loans & PAYDEX score & $\%$ PAYDEX $>70$ \\
\hline \multirow[t]{2}{*}{ Conventional } & $-0.0837 * *$ & 7.124 & 0.126 & 0.000781 & -552.0 & -216.0 \\
\hline & $(0.0416)$ & (5.294) & $(0.113)$ & $(0.0145)$ & $(32,539)$ & $(131,072)$ \\
\hline \multirow[t]{2}{*}{ Bias-corrected } & $-0.0687 *$ & 7.004 & 0.122 & 0.00274 & $-24,588$ & $-87,420$ \\
\hline & $(0.0416)$ & (5.294) & $(0.113)$ & $(0.0145)$ & $(32,539)$ & $(131,072)$ \\
\hline \multirow[t]{2}{*}{ Robust } & -0.0687 & 7.004 & 0.122 & 0.00274 & $-24,588$ & $-87,420$ \\
\hline & $(0.0473)$ & $(6.024)$ & $(0.127)$ & $(0.0174)$ & $(34,250)$ & $(143,173)$ \\
\hline Observations & 73366 & 73366 & 73366 & 73366 & 73366 & 73366 \\
\hline Kernel Type & Epanechnikov & Epanechnikov & Epanechnikov & Epanechnikov & Epanechnikov & Epanechnikov \\
\hline BW Type & mserd & mserd & mserd & mserd & mserd & mserd \\
\hline Sample & Total & Total & Total & Total & Total & Total \\
\hline Order Loc.Poly.(p) & 1.000 & 1.000 & 1.000 & 1.000 & 1.000 & 1.000 \\
\hline Order Bias(q) & 2.000 & 2.000 & 2.000 & 2.000 & 2.000 & 2.000 \\
\hline BW Loc.Poly.(h) & 7.833 & 9.231 & 9.143 & 5.370 & 6.170 & 5.825 \\
\hline BW Bias (b) & 14.549 & 17.487 & 18.260 & 8.580 & 18.384 & 13.732 \\
\hline
\end{tabular}

Note: The outcome variables are the probability of an unexpected increase of at least $20 \%$ in either the number or the total amount of bank loans made to small firms, the one-year forward tract-level average trade credit score of small firms and the proportion of firms with a trade credit score of more than 70. Covariates include the tract's population, the proportion of minority populations, the MFI, and the number of small and large bank branches. Conventional estimator of RD is based on the first order (linear) polynomial estimators in (3.4) and (3.5). (Robust) Bias-corrected is the first order polynomial RD estimators in (3.6) (columns (1) and (4)) and in (3.7) (Columns (2)-(3) and (5)-(6)). Alternative cutoff points of the MFI ratio are 70\% and 90\%. Standard errors in parentheses. Reported bandwidths are percentage points of the MFI ratio. Significance levels are ***1\%, **5\%, and *10\%.

conclude that there is no discontinuity in small firms' trade credit scores beyond the one induced by CRA eligibility at the cutoff value of $80 \%$.

Our third and final falsification exercise examines whether our findings are sensitive to the existence of a few tracts that are located very close to the cutoff point. This test is useful for assessing whether the results are robust to the unavoidable extrapolation involved in local polynomial estimation, as the observations nearest to the cutoff are more influential data points since they receive the higher kernel weights. If the exclusion of those tracts changes the significance of the results, then the external validity of the findings is in doubt. Excluding such tracts and then repeating the estimation using the remaining sample is sometimes referred to as a "donut hole" approach. Accordingly, we remove tracts that are within a radius of $2 \%$ from the MFI ratio's cutoff point, which total approximately $3.4 \%$ of the full sample of census tracts. The results in Table 11 show that the estimated CRA-eligibility effects on the probability of an unexpected increase in bank loans to small firms, on firms' average PAYDEX score, and on the proportion of firms with a PAYDEX score exceeding 70 remain statistically significant and economically equivalent to the main results. 
Table 11: Continuity-based analysis for the donut-hole approach $\mathrm{MFI}<78 \%$ or MFI $>82 \%$

\begin{tabular}{|c|c|c|c|c|c|c|}
\hline VARIABLES & $\begin{array}{c}\text { (1) } \\
\text { Bank loans }\end{array}$ & $\begin{array}{c}\text { (2) } \\
\text { Bank loans }\end{array}$ & $\begin{array}{c}(3) \\
\text { PAYDEX score }\end{array}$ & $\begin{array}{c}\text { (4) } \\
\text { PAYDEX score }\end{array}$ & $\begin{array}{c}(5) \\
\% \text { PAYDEX }>70\end{array}$ & $\begin{array}{c}(6) \\
\% \text { PAYDEX > } 70\end{array}$ \\
\hline Conventional & $\begin{array}{l}0.213 * * * \\
(0.0360)\end{array}$ & $\begin{array}{l}0.309 * * * \\
(0.0363)\end{array}$ & $\begin{array}{l}2.584 * * * \\
(0.805)\end{array}$ & $\begin{array}{l}2.239^{* *} \\
(0.885)\end{array}$ & $\begin{array}{c}0.0630 * * * \\
(0.0201)\end{array}$ & $\begin{array}{c}0.0583^{* * * *} \\
(0.0222)\end{array}$ \\
\hline Bias-corrected & $\begin{array}{l}0.216 * * * \\
(0.0360)\end{array}$ & $\begin{array}{l}0.312 * * * \\
(0.0363)\end{array}$ & $\begin{array}{c}2.589 * * * \\
(0.805)\end{array}$ & $\begin{array}{c}2.274 * * \\
(0.885)\end{array}$ & $\begin{array}{c}0.0608 * * * \\
(0.0201)\end{array}$ & $\begin{array}{c}0.0604 * * * \\
(0.0222)\end{array}$ \\
\hline Robust & $\begin{array}{c}0.216 * * * \\
(0.0442)\end{array}$ & $\begin{array}{c}0.312 * * * \\
(0.0443)\end{array}$ & $\begin{array}{c}2.589 * * * \\
(0.965)\end{array}$ & $\begin{array}{c}2.274 * * \\
(1.072)\end{array}$ & $\begin{array}{c}0.0608 * * \\
(0.0239)\end{array}$ & $\begin{array}{c}0.0604 * * \\
(0.0268)\end{array}$ \\
\hline Observations & 70769 & 12554 & 70769 & 12554 & 70769 & 12554 \\
\hline $\begin{array}{l}\text { Kernel Type } \\
\text { BW Type }\end{array}$ & $\begin{array}{l}\text { Epanechnikov } \\
\text { mserd }\end{array}$ & $\begin{array}{c}\text { Epanechnikov } \\
\text { mserd }\end{array}$ & $\begin{array}{l}\text { Epanechnikov } \\
\text { mserd }\end{array}$ & $\begin{array}{l}\text { Epanechnikov } \\
\text { mserd }\end{array}$ & $\begin{array}{c}\text { Epanechnikov } \\
\text { mserd }\end{array}$ & $\begin{array}{l}\text { Epanechnikov } \\
\text { mserd }\end{array}$ \\
\hline Sample & Total & Matched & Total & Matched & Total & Matched \\
\hline Order Loc.Poly.(p) & 1.000 & 1.000 & 1.000 & 1.000 & 1.000 & 1.000 \\
\hline Order Bias(q) & 2.000 & 2.000 & 2.000 & 2.000 & 2.000 & 2.000 \\
\hline BW Loc.Poly.(h) & 10.317 & 10.653 & 15.226 & 10.847 & 16.089 & 11.162 \\
\hline BW Bias (b) & 22.219 & 23.411 & 36.664 & 23.962 & 40.693 & 24.798 \\
\hline
\end{tabular}

Note: The outcome variables are the probability of an unexpected increase of at least $20 \%$ in either the number or the total amount of bank loans made to small firms, the one-year forward tract-level average trade credit score of small firms and the proportion of firms with a trade credit score of more than 70. Covariates include the tract's population, the proportion of minority populations, the MFI, and the number of small and large bank branches. Conventional estimator of RD is based on the first order (linear) polynomial estimators in (3.4) and (3.5). (Robust) Bias-corrected is the first order polynomial RD estimators in (3.6) (columns (1) and (2)) and in (3.7) (columns (3)-(6)). Tracts with a MFI ratio within 2\% radius around the cutoff point of $80 \%$ are excluded from the sample. Reported bandwidths are percentage points of the MFI ratio. Standard errors in parentheses. Significance levels are $* * * 1 \%, * * 5 \%$, and $* 10 \%$.

\section{Conclusion}

This study presented a model that shows when a local market has few banks and competition is low, small firms that are distant from banks prefer trade credit due to their high costs of applying for bank loans and the high monopoly loan rates charged by banks. Hence in this equilibrium, some small firms are "unbanked" and rely on trade credit. In contrast, when a local market has many banks, firms' costs of applying for loans are lower since they are closer to a bank and, moreover, bank loan rates are lower due to greater competition. In equilibrium, all small firms obtain bank loans and none resort to relatively expensive trade credit. The model also predicts that if a government regulation, such as the CRA, designates the local market as an LMI area and incentivizes its banks to expand lending, this regulation has its greatest impact on markets with few banks. While bank loan rates fall to generate greater lending in all CRA-eligible markets, only in markets with low bank competition are there reductions in unbanked firms that resorted to trade credit.

Our empirical findings are consistent with these model predictions. When a census tract becomes newly eligible for CRA lending, there is a greater probability of a large, unexpected increase in bank lending to that tract compared to tracts that remain ineligible. However, only in tracts characterized by low bank 
competition is there a significant reduction in small firms' use of trade credit. The reduction is especially pronounced when a firm operates in an industry that traditionally depended on trade credit. Our study's results confirm past research showing that the CRA tends to expand bank lending to small firms in LMI areas. But more importantly, it also shows that the CRA provides a direct economic benefit to small firms by allowing them to substitute bank credit for the relatively more expensive trade credit in those LMI areas where bank competition is weak.

These findings suggest the following policy recommendations. Government intervention may be necessary to reduce unbanked small firms' reliance on relatively expensive sources of financing, such as trade credit. One way to accomplish this goal is through CRA-type regulations that incent banks to expand lending to LMI areas. While LMI areas tend to have higher bank concentration than UMI areas, the regulation might be most effective if it focuses rewards for lending in those areas with less bank competition. As an alternative, or in addition, to CRA regulation, government interventions might take the form of policies that promote greater bank competition in LMI areas that are currently served by few banks. For example, encouraging the entry of bank branches in underserved areas might promote greater competition in lending to small firms.

Although our study sheds new light on the relationship between bank and trade credit as well as the relationship between CRA regulation and competition, it raises a number of other interesting issues for future research. Further investigation may be warranted to determine the CRA's effect on the suppliers of trade credit. The CRA could benefit a small firm's vendors and suppliers by shortening the trade credit period, though its ultimate effect needs to account for potential losses from early-payment discounts or from the elimination of late-payment fees. Furthermore, our paper has focused on bank competition with trade credit being a firm's only source of nonbank financing. Yet the recent growth in online marketplace lending offers an additional source of funding that could strengthen competition and reduce the need for the CRA. However, online marketplace lending may be less likely to address the credit needs of borrowers with high screening costs, such as small and minority-owned firms, located in LMI areas. Finally, further research is warranted on the CRA's impact on other economic aspects of small firms, such as their employment, overall profitability, and growth. 


\section{References}

Agarwal, S., E. Benmelech, N. Bergman, and A. Seru (2012). Did the Community Reinvestment Act (CRA) lead to risky lending? Technical report, National Bureau of Economic Research.

Agarwal, S. and R. Hauswald (2010). Distance and private information in lending. The Review of Financial Studies 23(7), 2757-2788.

Avery, R. B., R. W. Bostic, and G. B. Canner (2005). Assessing the necessity and efficiency of the Community Reinvestment Act. Housing Policy Debate 16(1), 143-172.

Avery, R. B. and K. P. Brevoort (2015). The subprime crisis: Is government housing policy to blame? Review of Economics and Statistics 97(2), 352-363.

Avery, R. B., P. S. Calem, and G. B. Canner (2003). The effects of the Community Reinvestment Act on local communities. Board of Governors of the Federal Reserve System Working Paper.

Barnatchez, K., L. Crane, and R. Decker (2017). An assessment of the national establishment time series (nets) database (finance and economics discussion series 2017-110). Washington, DC: Board of Governors of the Federal Reserve System. doi 10.

Basu, A., A. Basu, and C. Ingene (2021). Retail competition on Salop Circle under linear demand: Implications for distribution strategy. Working Paper, Syracuse University, Utica College, and University of Oklahoma.

Begley, T. A. and A. Purnanandam (2021). Color and credit: Race, regulation, and the quality of financial services. Journal of Financial Economics.

Berger, A. N., N. H. Miller, M. A. Petersen, R. G. Rajan, and J. C. Stein (2005). Does function follow organizational form? Evidence from the lending practices of large and small banks. Journal of Financial Economics 76(2), 237-269. 
Berger, A. N., A. Saunders, J. M. Scalise, and G. F. Udell (1998). The effects of bank mergers and acquisitions on small business lending. Journal of Financial Economics 50(2), 187-229.

Bhutta, N. (2011). The Community Reinvestment Act and mortgage lending to lower income borrowers and neighborhoods. The Journal of Law and Economics 54(4), 953-983.

Biais, B. and C. Gollier (1997). Trade credit and credit rationing. The Review of Financial Studies 10(4), 903-937.

Black, S. E. and P. E. Strahan (2002). Entrepreneurship and bank credit availability. The Journal of Finance 57(6), 2807-2833.

Bostic, R. W. and H. Lee (2017). Small business lending under the Community Reinvestment Act. Cityscape 19(2), 63-84.

Bostic, R. W. and B. L. Robinson (2003). Do CRA agreements influence lending patterns? Real Estate Economics 31(1), 23-51.

Brevoort, K., J. Holmes, and J. Wolken (2010). Distance still matters: The information revolution in small business lending and the persistent role of location, 1993-2003. Finance and Economics Discussion Series Working Paper 2010-08, Federal Reserve Board.

Calonico, S., M. D. Cattaneo, and R. Titiunik (2014). Robust nonparametric confidence intervals for regression-discontinuity designs. Econometrica 82(6), 2295-2326.

Cattaneo, M. D., N. Idrobo, and R. Titiunik (2019). A practical introduction to regression discontinuity designs: Foundations. Cambridge University Press.

Cetorelli, N. and P. E. Strahan (2006). Finance as a barrier to entry: Bank competition and industry structure in local US markets. The Journal of Finance 61(1), 437-461.

Dahl, D., D. D. Evanoff, and M. F. Spivey (2010). The Community Reinvestment Act and targeted mortgage lending. Journal of Money, Credit and Banking 42(7), 1351-1372. 
Ding, L., H. Lee, and R. Bostic (2018). Effects of the Community Reinvestment Act (CRA) on small business lending. FRB Philadelphia Working Paper.

Ding, L. and L. Nakamura (2020). Don't know what you got till it's gone - the Community Reinvestment Act in a changing financial landscape. The Community Reinvestment Act in a Changing Financial Landscape (February, 2020). FRB Philadelphia Working Paper (20-08).

Fisman, R. and I. Love (2003). Trade credit, financial intermediary development, and industry growth. The Journal of Finance 58(1), 353-374.

Greenstone, M., A. Mas, and H.-L. Nguyen (2020). Do credit market shocks affect the real economy? Quasi-experimental evidence from the great recession and "normal" economic times. American Economic Journal: Economic Policy 12(1), 200-225.

Heckman, J. J., R. J. LaLonde, and J. A. Smith (1999). The economics and econometrics of active labor market programs. In Handbook of Labor Economics, Volume 3, pp. 1865-2097.

Kim, M. J., K. M. Lee, and J. S. Earle (2021). Does the Community Reinvestment Act increase small business lending in lower income neighborhoods? IZA Discussion Paper.

Lee, D. S. and T. Lemieux (2010). Regression discontinuity designs in economics. Journal of Economic Literature 48(2), 281-355.

Marsico, R. D. (2005). The 2004-2005 amendments to the Community Reinvestment Act regulations: For communities, one step forward and three steps back. Clearinghouse Review 29, 534-545.

Mills, C. K., J. Battisto, and S. Lieberman (2019). Growing pains: Examining small business access to affordable credit in low-income areas. Consumer \& Community Content 1(2), 22-27.

Nguyen, H.-L. Q. (2019). Are credit markets still local? Evidence from bank branch closings. American Economic Journal: Applied Economics 11(1), 1-32. 
Petersen, M. A. and R. G. Rajan (1994). The benefits of lending relationships: Evidence from small business data. The Journal of Finance 49(1), 3-37.

Petersen, M. A. and R. G. Rajan (1995). The effect of credit market competition on lending relationships. The Quarterly Journal of Economics 110(2), 407-443.

Petersen, M. A. and R. G. Rajan (1997). Trade credit: theories and evidence. The Review of Financial Studies 10(3), 661-691.

Petersen, M. A. and R. G. Rajan (2002). Does distance still matter? The information revolution in small business lending. The Journal of Finance 57(6), 2533-2570.

Rice, T. and P. E. Strahan (2010). Does credit competition affect small-firm finance? The Journal of Finance 65(3), 861-889.

Salop, S. C. (1979). Monopolistic competition with outside goods. The Bell Journal of Economics, 141156.

Thisse, J.-F. and X. Vives (1988). On the strategic choice of spatial price policy. American Economic Review 78(1), 122-136.

Zinman, J. (2002). The efficacy and efficiency of credit market interventions: Evidence from the Community Reinvestment Act. Joint Center for Housing Studies of Harvard University Working Paper CRA02-2. 


\section{A Appendix: Model derivations}

This Appendix derives the equilibrium bank loan rates, loan quantities, and proportions of small firms receiving bank loans for the model's three types of equilibria: local monopoly, competitive, and kinked.

\section{A.1 Local monopoly equilibrium}

Consider the case where the number of banks, $n$, is sufficiently small so that each bank competes for small firms' borrowing with trade creditors rather than neighboring banks. A firm at a distance $x$ from a bank has nonzero demand for the bank's loan if inequality (2.2) holds. Therefore, define $\bar{x}\left(r_{L}\right) \equiv \frac{b}{t}\left(r_{T}-r_{L}\right)$ to be the distance from a bank where, at the bank loan rate $r_{L}$, a firm is indifferent between borrowing from the bank or trade creditors. If, in equilibrium, $\bar{x}\left(r_{L}\right)<\frac{1}{2 n}$, then there is no competition between neighboring banks and a local monopoly equilibrium. In this case, accounting for small firms on both sides of the bank, the monopolist bank's total quantity of loans is

$$
\begin{aligned}
Q & =2 B\left(r_{L}\right) \bar{x}\left(r_{L}\right) \\
& =2\left(a-b r_{L}\right) \bar{x}\left(r_{L}\right) .
\end{aligned}
$$

The bank's profit function is then:

$$
\begin{aligned}
\Pi & =\left(r_{L}-r_{F}\right) 2\left(a-b r_{L}\right) \bar{x}\left(r_{L}\right) \\
& =\left(r_{L}-r_{F}\right) 2 b\left(a / b-r_{L}\right) \frac{b}{t}\left(r_{T}-r_{L}\right) \\
& =2 \frac{b^{2}}{t}\left(r_{L}-r_{F}\right)\left(a / b-r_{L}\right)\left(r_{T}-r_{L}\right) .
\end{aligned}
$$

The choice of $r_{L}$ that maximizes profits leads to the first order condition:

$$
\frac{\partial \Pi}{\partial r_{L}}=2 \frac{b^{2}}{t}\left[\left(a / b-r_{L}\right)\left(r_{T}-r_{L}\right)+\left(r_{L}-r_{F}\right)\left(-\left(r_{T}-r_{L}\right)-\left(a / b-r_{L}\right)\right)\right]=0,
$$


which is a quadratic equation of $r_{L}$ that can be rearranged as:

$$
3 r_{L}^{2}-2\left(r_{T}+a / b+r_{F}\right) r_{L}+c=0
$$

where $c \equiv r_{T} a / b+r_{F}\left(r_{T}+a / b\right)>0$. The solution satisfies:

$$
r_{L}=\frac{1}{3}\left(r_{T}+a / b+r_{F}\right) \pm \frac{1}{3} \sqrt{\left(r_{T}+a / b+r_{F}\right)^{2}-3 c}
$$

The positive root implies $r_{L}>r_{T}$ so that all small firms would choose to borrow from trade creditors and banks would make no loans. Therefore, the economically relevant solution is the negative root that leads to equation (2.3) in the text. Based on equation (A.1), the quantity of loans made by each bank is:

$$
\begin{aligned}
Q_{M} & =2\left(a-b r_{L}\right) \bar{x}\left(r_{L}\right) \\
& =2 \frac{b^{2}}{t}\left(\frac{a}{b}-r_{L}\right)\left(r_{T}-r_{L}\right),
\end{aligned}
$$

and substituting the expression for $r_{L}$ from equation (2.3) into equation (A.6) leads to the value of $Q_{M}$ given by equation (2.4) in the text. Also, note that the proportion of small firms obtaining bank loans equals:

$$
\rho_{M} \equiv \frac{\bar{x}\left(r_{L}\right)}{1 /(2 n)}=2 n \frac{b}{t}\left(r_{T}-r_{L}\right)
$$

and, again, substituting the expression for $r_{L}$ from equation (2.3) into equation (A.7) leads to the value of $\rho_{M}$ given by equation $(2.5)$ in the text.

\section{A.2 Competitive equilibrium}

When $n$ is sufficiently large, banks compete with neighboring banks when making loans to small firms, and in equilibrium no firm uses trade credit. Let banks be indexed consecutively around the market circle by $i, i=1, \ldots, n$. We can determine bank $i$ 's quantity of loans made, $Q_{i}$, as follows. Suppose a small firm is located at a distance $x \in\left[0, \frac{1}{n}\right]$ from bank $i$ and a distance $\left(\frac{1}{n}-x\right)$ from bank $i-1$, and bank $i$ sets the 
loan rate $r_{L, i}$ while bank $i-1$ sets the loan rate $r_{L}$. Then this firm is indifferent between borrowing from these two banks when:

$$
\begin{aligned}
B\left(r_{L, i}\right)-t x & =B\left(r_{L}\right)-t\left(\frac{1}{n}-x\right) \\
a-b r_{L, i}-t x & =a-b r_{L}-t\left(\frac{1}{n}-x\right)
\end{aligned}
$$

which implies

$$
x=\frac{b}{2 t}\left(r_{L}-r_{L, i}\right)+\frac{1}{2 n} .
$$

Similarly, another small firm located a distance $x \in\left[0, \frac{1}{n}\right]$ from bank $i$ and $\left(\frac{1}{n}-x\right)$ from bank $i+1$ will also be indifferent when equation (A.9) holds. Thus, considering small firms on both sides of bank $i$, its total quantity of loans equals:

$$
\begin{aligned}
Q_{i} & =2 x B\left(r_{L, i}\right)=2 x\left(a-b r_{L, i}\right) \\
& =2 x b\left(a / b-r_{L, i}\right) .
\end{aligned}
$$

Therefore, bank $i$ 's profit function is:

$$
\begin{aligned}
\Pi_{i} & =Q_{i}\left(r_{L, i}-r_{F}\right) \\
& =2 x b\left(a / b-r_{L, i}\right)\left(r_{L, i}-r_{F}\right) \\
& =2 x b\left[m\left(r_{L, i}-r_{F}\right)-\left(r_{L, i}-r_{F}\right)^{2}\right],
\end{aligned}
$$

where $m \equiv\left(a / b-r_{F}\right)$. Given the value of $x$ in equation (A.9), $\frac{\partial x}{\partial r_{L, i}}=-\frac{b}{2 t}$. Hence, the first order condition implies that the profit maximizing choice of $r_{L, i}$ satisfies:

$$
\frac{\partial \Pi_{i}}{\partial r_{L, i}}=-\frac{b^{2}}{t}\left[m\left(r_{L, i}-r_{F}\right)-\left(r_{L, i}-r_{F}\right)^{2}\right]+2 x b\left[m-2\left(r_{L, i}-r_{F}\right)\right]=0 .
$$


In a symmetric, Bertrand-Nash equilibrium, $r_{L, i}=r_{L}$, which implies $x=\frac{1}{2 n}$. Hence, the equilibrium value of $r_{L}$ satisfies:

$$
-\frac{b}{t}\left[m\left(r_{L}-r_{F}\right)-\left(r_{L}-r_{F}\right)^{2}\right]+\frac{1}{n}\left[m-2\left(r_{L}-r_{F}\right)\right]=0
$$

or

$$
\left(r_{L}-r_{F}\right)^{2}-\left(m+\frac{2 t}{b n}\right)\left(r_{L}-r_{F}\right)+\frac{m t}{b n}=0
$$

so that

$$
r_{L}-r_{F}=\frac{1}{2} m+\frac{t}{b n} \pm \sqrt{\frac{m^{2}}{4}+\left(\frac{t}{b n}\right)^{2}} .
$$

Note that the positive root cannot be the relevant economic solution since it implies $r_{L}-r_{F}>m=$ $a / b-r_{F}$ or $r_{L}>a / b$, in which case there would be zero demand for bank loans. Hence, the solution uses the negative root, which leads to the value of $r_{L}$ given in equation (2.7) of the text. Since in equilibrium $x=\frac{1}{2 n}$ when the competitive equilibrium holds, substituting the solution for $r_{L}$ in (2.7) into equation (A.10) leads to equation (2.8) in the text.

This competitive equilibrium can hold only if the small firm that is farthest from a bank at the distance $x=\frac{1}{2 n}$ continues to prefer bank loan financing rather than trade credit financing, $B\left(r_{L}\right)-\frac{t}{2 n}>B\left(r_{T}\right)$, or

$$
r_{T}-r_{L}>\frac{t}{2 b n}
$$

Substituting the solution for $r_{L}$ in (2.7) into inequality (A.16) leads to inequality (2.9) in the text.

\section{A.3 Kinked equilibrium}

Note that the condition on the number of banks required for the monopoly equilibrium to obtain is $n<n_{M}$, where $n_{M}$ is given by equation (2.6) in the text. Also note that $n>n_{C}$ for the competitive equilibrium to hold, where $n_{C}$ is the value of $n$ such that inequality (2.9) holds with equality. We now give an example showing that $n_{M}<n_{C}$ so that there exist values of $n$ where $n_{M}<n<n_{C}$ and neither the monopoly equi- 
librium nor the competitive equilibrium holds. ${ }^{25}$ To show that this possibility exists, consider the following example where $r_{F}=0.07, r_{T}=0.4, \frac{a}{b}=0.5, b=0.4$, and $t=0.6$. Then, for these parameters, $n_{M}=3.63$ and $n_{C}=4.27$. Therefore, $n=4$ banks would result in a kinked equilibrium.

Based on the same logic as Salop (1979), the kinked equilibrium bank loan is that for which the firms farthest from a bank at the distance $x=\frac{1}{2 n}$ are indifferent between borrowing from a bank or trade creditors:

$$
\begin{aligned}
B\left(r_{L}\right)-\frac{t}{2 n} & =B\left(r_{T}\right) \\
a-b r_{L}-\frac{t}{2 n} & =a-b r_{T} .
\end{aligned}
$$

Solving for $r_{L}$ leads to $r_{L}=r_{T}-\frac{t}{2 n b}$, which is equation (2.10) in the text. Therefore, each bank's quantity of loans equals:

$$
Q_{K}=2 \frac{1}{2 n} B\left(r_{L}\right)=\frac{a-b r_{L}}{n}
$$

Substituting the value of $r_{L}$ in equation (2.10) into equation (A.18) leads to equation (2.11) in the text.

\footnotetext{
${ }^{25}$ Our analysis has not imposed an integer constraint on values of $n$. If that was done, under particular parameter values, it may be the case that there are no integer values of $n$ for which neither the monopoly nor the competitive equilibria hold. That is, there are no integer values of $n$ for which the alternative kinked equilibrium exists.
} 